Prepared in cooperation with the U.S. Army Corps of Engineers

\title{
Improved Algorithms in the CE-QUAL-W2 Water-Quality Model for Blending Dam Releases to Meet Downstream Water-Temperature Targets
}

Open-File Report 2015-1027 



\title{
Improved Algorithms in the CE-QUAL-W2 Water-Quality Model for Blending Dam Releases to Meet Downstream Water-Temperature Targets
}

\author{
By Stewart A. Rounds and Norman L. Buccola
}

Prepared in cooperation with the U.S. Army Corps of Engineers

Open-File Report 2015-1027 


\section{U.S. Department of the Interior \\ SALLY JEWELL, Secretary}

\section{U.S. Geological Survey \\ Suzette M. Kimball, Acting Director}

U.S. Geological Survey, Reston, Virginia: 2015

For more information on the USGS-the Federal source for science about the Earth,

its natural and living resources, natural hazards, and the environment-visit

http://www. usgs.gov or call 1-888-ASK-USGS

For an overview of USGS information products, including maps, imagery, and publications, visit $h$ ttp://www.usgs.gov/pubprod

To order this and other USGS information products, visit http://store.usgs.gov

Any use of trade, firm, or product names is for descriptive purposes only and does not imply endorsement by the U.S. Government.

Although this information product, for the most part, is in the public domain, it also may contain copyrighted materials as noted in the text. Permission to reproduce copyrighted items must be secured from the copyright owner.

Suggested citation:

Rounds, S.A., and Buccola, N.L., 2015, Improved algorithms in the CE-QUAL-W2 water-quality model for blending dam releases to meet downstream water-temperature targets: U.S. Geological Survey Open-File Report 2015-1027, 40 p., http://dx.doi.org/10.3133/ofr20151027.

ISSN 2331-1258 (online) 


\section{Contents}

Abstract

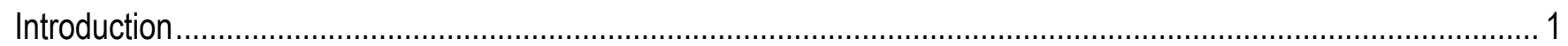

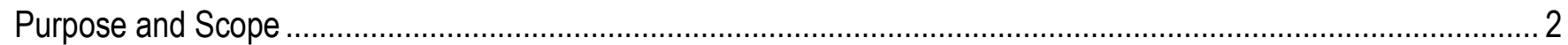

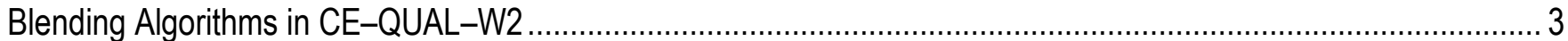

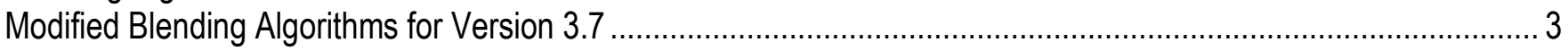

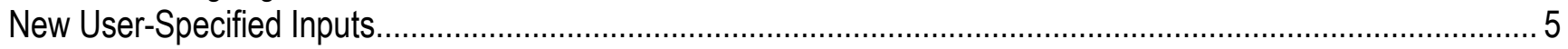

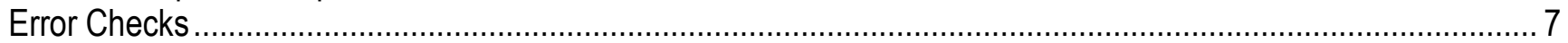

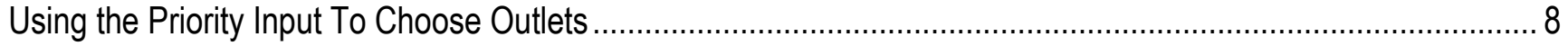

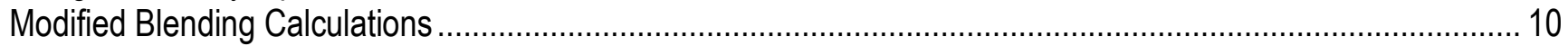

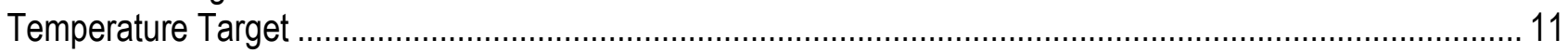

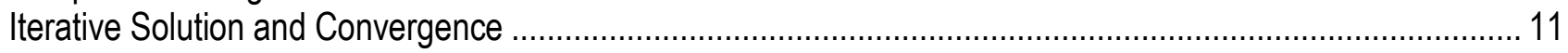

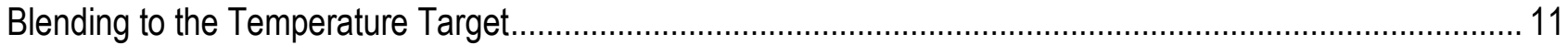

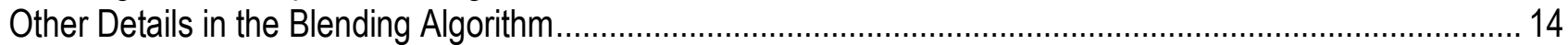

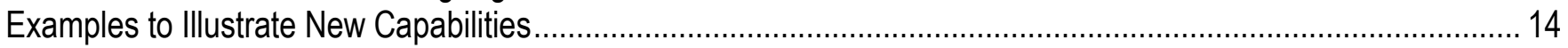

Example 1: Power Production Shared with Spillway or Regulating Outlet ..................................................... 14

Example 2: Floating and Fixed Outlets with a Nonblended Release ........................................................... 16

Example 3: Eight Fixed Gates with Ranked Priorities ........................................................................... 18

Example 4: Eight Fixed Gates with Identical Priorities .............................................................................. 20

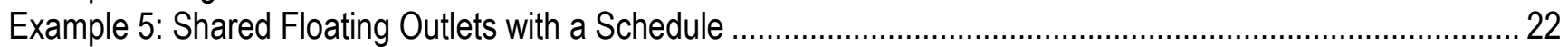

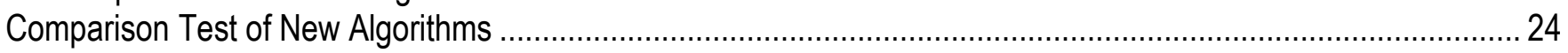

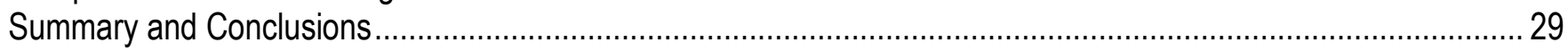

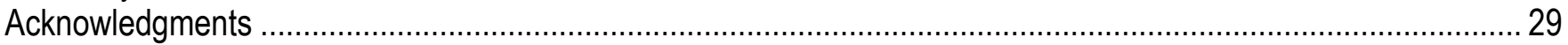

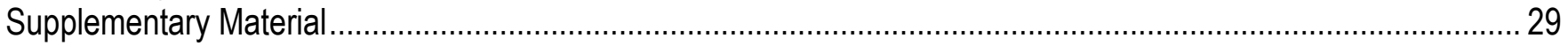

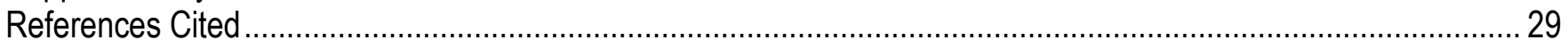

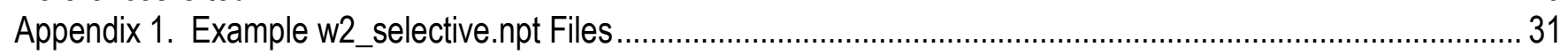




\section{Figures}

Figure 1. Schematic showing examples of configurations of floating and fixed-elevation outlets that can be simulated by the modified model to blend releases to meet a downstream temperature target.

Figure 2. Flow chart for determining which outlets are available and used, and for assigning those outlets to the nonblended group - high-priority set A and low-priority set B

Figure 3. Flow chart for determining the temperature target, allocating flows among the outlets in sets $A$ and $B$, and iterating to converge to an optimum blending solution that best meets the temperature target.

Figure 4. Example 1 uses three fixed-elevation outlets, in which the power outlet has the highest priority and is assigned at least 40 percent of the total release, and the regulating outlet (RO) has a maximum head constraint of 50 meters

Figure 5. Example 2 uses a nonblended outlet (priority -1) and blends the remaining releases among a floating outlet and two fixed-elevation outlets.

Figure 6. Example 3 uses a tower of eight fixed-elevation gates, in which the priorities are assigned to ensure that releases are blended between the lowest outlet (highest priority of 1) and the highest available outlet

Figure 7. Example 4 uses a tower of eight fixed-elevation gates, in which the priorities are all identical

Figure 8. Example 5 uses two floating outlets that share the flow for the lower priority (set B) outlets because TSSHARE is set to ON

Figure 9. Map showing location of Detroit Lake and Detroit Dam in the North Santiam River Basin, northwestern Oregon

Figure 10. Outlets and user specifications for the Detroit Lake comparison test......

Figure 11. Comparison of daily mean release temperatures resulting from the use of blending algorithms in CE-QUAL-W2 version 3.1.2 (v3.1) and version 3.7 (v3.7) and applied to Detroit Lake, northwestern Oregon, for three environmental conditions: (A) cool/wet, (B) normal, and (C) hot/dry....

Figure 12. Difference in the daily mean release temperatures (version 3.7 results minus version 3.1 .2 results) from the "uro-float_400fmin" scenario as applied to Detroit Lake, northwestern Oregon, for three sets of environmental conditions (cool/wet, normal, and hot/dry).

\section{Table}

Table 1. Description of user-specified inputs in the w2_selective.npt file for blending. 


\section{Conversion Factors and Abbreviations and Acronyms}

\section{Conversion Factors}

Inch/Pound to SI

\begin{tabular}{lcll}
\hline & Multiply & By & \multicolumn{1}{c}{ To obtain } \\
\hline foot $(\mathrm{ft})$ & 0.3048 & meter $(\mathrm{m})$ \\
mile (mi) & 1.609 & kilometer $(\mathrm{km})$ \\
cubic foot $\left(\mathrm{ft}^{3}\right)$ & 0.02832 & cubic meter $\left(\mathrm{m}^{3}\right)$ \\
acre-foot $(\mathrm{acre}-\mathrm{ft})$ & 1,233 & cubic meter $\left(\mathrm{m}^{3}\right)$ \\
cubic foot per second $\left(\mathrm{ft}^{3} / \mathrm{s}\right)$ & 0.02832 & cubic meter per second $\left(\mathrm{m}^{3} / \mathrm{s}\right)$ \\
\hline
\end{tabular}

SI to Inch/Pound

\begin{tabular}{|c|c|c|}
\hline Multiply & By & To obtain \\
\hline meter (m) & 3.281 & foot $(\mathrm{ft})$ \\
\hline kilometer $(\mathrm{km})$ & 0.6214 & mile (mi) \\
\hline cubic meter $\left(\mathrm{m}^{3}\right)$ & 35.31 & cubic foot $\left(\mathrm{ft}^{3}\right)$ \\
\hline cubic meter $\left(\mathrm{m}^{3}\right)$ & 0.0008107 & acre-foot (acre-ft) \\
\hline cubic meter per second $\left(\mathrm{m}^{3} / \mathrm{s}\right)$ & 35.31 & cubic foot per second $\left(\mathrm{ft}^{3} / \mathrm{s}\right)$ \\
\hline
\end{tabular}

Temperature in degrees Celsius $\left({ }^{\circ} \mathrm{C}\right)$ may be converted to degrees Fahrenheit $\left({ }^{\circ} \mathrm{F}\right)$ as follows:

$$
{ }^{\circ} \mathrm{F}=\left(1.8 \times{ }^{\circ} \mathrm{C}\right)+32 \text {. }
$$

Temperature in degrees Fahrenheit $\left({ }^{\circ} \mathrm{F}\right)$ may be converted to degrees Celsius $\left({ }^{\circ} \mathrm{C}\right)$ as follows:

$$
{ }^{\circ} \mathrm{C}=\left({ }^{\circ} \mathrm{F}-32\right) / 1.8 \text {. }
$$

\section{Abbreviations and Acronyms}

\begin{tabular}{ll}
\hline \multicolumn{1}{c}{ Name } & \multicolumn{1}{c}{ Description } \\
\hline CE-QUAL-W2 & Two-dimensional hydrodynamic and water-quality model \\
USACE & U.S. Army Corps of Engineers \\
USGS & U.S. Geological Survey \\
\hline
\end{tabular}


This page left intentionally blank 


\title{
Improved Algorithms in the CE-QUAL-W2 Water-Quality Model for Blending Dam Releases to Meet Downstream Water-Temperature Targets
}

\author{
By Stewart A. Rounds and Norman L. Buccola
}

\begin{abstract}
Water-quality models allow water resource professionals to examine conditions under an almost unlimited variety of potential future scenarios. The two-dimensional (longitudinal, vertical) waterquality model CE-QUAL-W2, version 3.7, was enhanced and augmented with new features to help dam operators and managers explore and optimize potential solutions for temperature management downstream of thermally stratified reservoirs. Such temperature management often is accomplished by blending releases from multiple dam outlets that access water of different temperatures at different depths. The modified blending algorithm in version 3.7 of CE-QUAL-W2 allows the user to specify a time-series of target release temperatures, designate from 2 to 10 floating or fixed-elevation outlets for blending, impose minimum and maximum head and flow constraints for any blended outlet, and set priority designations for each outlet that allow the model to choose which outlets to use and how to balance releases among them. The modified model was tested with a variety of examples and against a previously calibrated model of Detroit Lake on the North Santiam River in northwestern Oregon, and the results compared well. These updates to the blending algorithms will allow more complicated damoperation scenarios to be evaluated somewhat automatically with the model, with decreased need for multiple model runs or preprocessing of model inputs to fully characterize the operational constraints.
\end{abstract}

\section{Introduction}

CE-QUAL-W2 is a two-dimensional, laterally averaged hydrodynamic and water-quality model developed by the U.S. Army Corps of Engineers (USACE) and Portland State University (Cole and Wells, 2011). It is well suited for the simulation of long, narrow water bodies that tend to thermally stratify. The model simulates flow, water level, horizontal and vertical velocities, water temperature, ice cover, and many water-quality constituents, such as ammonia, nitrate, phosphate, dissolved and particulate organic matter, suspended sediment, various types of algae and macrophytes, $\mathrm{pH}$, and dissolved oxygen. It has been applied successfully to hundreds of reservoirs, lakes, gently sloping rivers, and estuarine systems around the world (Cole and Wells, 2011). U.S. Geological Survey (USGS) personnel have applied the model to various rivers and reservoirs in Oregon to simulate water circulation and water temperature (Sullivan and others, 2007; Risley and others, 2010; Rounds, 2010; Buccola and others, 2012) and more complicated water-quality conditions (Rounds and Wood, 2001; Sullivan and Rounds, 2006; Sullivan and others, 2013). 
The CE-QUAL-W2 model has been used in several Oregon applications to assess the efficacy of strategies to mitigate the downstream temperature effects of high-head dams (Buccola and others, 2012). Such dams often release cold water in mid-summer from below the lake's thermocline and then release stored summer heat in autumn as the lake is drawn down to make room for flood management purposes in winter. The altered seasonal pattern in water temperature can affect the timing of fish migration, spawning, and egg emergence (Collier and others, 1996; Caissie, 2006). Temperatures released from these dams can be managed by blending flows from two or more dam outlets, however, and CE-QUAL-W2 can be configured to predict the results of operational strategies and structural options to try to meet downstream temperature targets by adjusting the use of the available outlets.

In the Pacific Northwest of the United States, many species of anadromous fish are classified as threatened or endangered. Water-quality standards, total maximum daily load programs, and restoration plans all have been crafted to help those fish species survive and recover. In the Willamette River Basin in northwestern Oregon, a Biological Opinion provides a framework for the protection and restoration of habitat for several species of endangered salmon and steelhead (National Marine Fisheries Service, 2008). The Biological Opinion requires the USACE to evaluate and implement feasible operational and/or structural modifications at their Willamette River Basin dams to address the flow and temperature effects of those dams. Calibrated CE-QUAL-W2 models of many of the Willamette River Basin reservoirs are available.

The capability to blend releases from dam outlets to meet a downstream temperature target was added to CE-QUAL-W2 only in recent versions. Before such a capability was built into the model, multiple model runs were required in an iterative fashion to determine an optimal dam-operations strategy that might best be used to meet a downstream temperature target (Hanna and others, 1999). Later, Rounds and Sullivan (2006) modified version 3.1.2 of the CE-QUAL-W2 code to bring blending calculations into the model, allowing optimized dam operations to be carried out in a single model run; however, those code modifications were not incorporated into the public-release version of the model. The off-the-shelf version 3.7 CE-QUAL-W2 model (Cole and Wells, 2011) included an algorithm to blend releases from two dam outlets to meet a temperature target, but the capabilities of that algorithm were limited. The modifications described in this report were focused on expanding the blending capabilities of the version 3.7 model by adding new features and capabilities so that a greater number of operational and structural strategies could be evaluated with some useful outlet-specific constraints. The new capabilities were tested with a model of Detroit Lake, one of the Willamette River Basin reservoirs where blending strategies are being evaluated and used to improve and restore downstream temperatures.

\section{Purpose and Scope}

This report documents the modification of blending routines for dam releases in version 3.7 of the CE-QUAL-W2 model. The model source code was modified to add new functionality and new input parameters that allow the user to configure and constrain the characteristics of dam outlets in the model, and mix releases from more outlets, in ways that previously were not possible. The modified model was tested and results were compared with those from a previously calibrated version 3.1.2 CE-QUAL-W2 model of Detroit Lake, Oregon, using several sets of imposed environmental forcings that include $\mathrm{cool} / \mathrm{wet}$, normal, and hot/dry conditions drawn from the historical record. The documented model source code and compiled binaries are available for download (see section, "Supplementary Material"). 


\section{Blending Algorithms in CE-QUAL-W2}

Version 3.7 of CE-QUAL-W2 includes two different algorithms for releasing water from a dam to meet a downstream temperature target (Cole and Wells, 2011). The first algorithm essentially implements a variable-elevation outlet or "temperature control device" in which a single structure or withdrawal is allowed up to 10 discrete elevations to which it can be set, one elevation at a time, to keep a user-specified control point cooler than a user-specified temperature target. That control point can be at the point of the tower or downstream. The second algorithm implements the blending of releases from two specified structures or withdrawals to match a user-specified release temperature. The upper of the two outlets can be set to follow the water-surface elevation to mimic a floating outlet, and many separate temperature targets can be set for different date ranges to approximate a time-series target. This blending algorithm, however, is limited to only two outlets and has few options to allow for detailed user control of the blending.

Prior to the existence of an outlet-blending routine in the off-the-shelf version of CE-QUAL-W2, a relatively flexible blending algorithm was programmed into version 3.1.2 of CE-QUAL-W2 (Cole and Wells, 2002) by Rounds and Sullivan (2006). The blending algorithm allowed for the specification of fixed-elevation, floating, or sliding-gate (variable-elevation) outlets, and enabled the model to blend releases from multiple outlets (choosing the best two outlets if more than two were available) in an attempt to meet a user-specified time-series temperature target. That algorithm was utilized and performed well in applications of the model to Henry Hagg Lake (Sullivan and Rounds, 2006) and Detroit Lake (Sullivan and others, 2007) in northwestern Oregon. Subsequently, the blending algorithm was enhanced with an iterative solution technique and the addition of several options: (1) specification of the depth of floating outlets, (2) assignment of a minimum outlet flow rate or minimum fraction of the total release rate to a particular outlet, and (3) an outlet priority setting that helped to resolve conflicts in minimum-flow assignments or determine outlet usage in isothermal settings (Buccola and Rounds, 2011; Buccola and others, 2012).

\section{Modified Blending Algorithms for Version 3.7}

To take advantage of a more recent version (3.7 as opposed to 3.1.2) of CE-QUAL-W2 and yet retain some of the features of the blending algorithms that had been added to version 3.1.2, modifications were made to the version 3.7 model based on the source code released April 26, 2012 (Portland State University Water Quality Research Group, 2012). Most of the code changes were made to the withdrawal.f90 source file, with other minor modifications elsewhere; all modified source code is available for download (see section, "Supplementary Material") and the modified w2_selective.npt file format is documented in the examples in the appendix 1. Few modifications were made to the "temperature control device" portion of the version 3.7 code; most of the changes were associated with the "blending" code that mixes releases from two or more outlets.

In short, code changes were made to allow blending from up to 10 outlets (see the example outlet configurations in fig. 1) to meet a user-specified time-series temperature target, and user inputs were added to specify the depth of floating outlets, optional constraints on minimum and maximum head and release rates for each outlet, and a priority ranking for each outlet, among others. An iterative solution technique also was added to ensure that the blending calculations were as accurate as possible. 

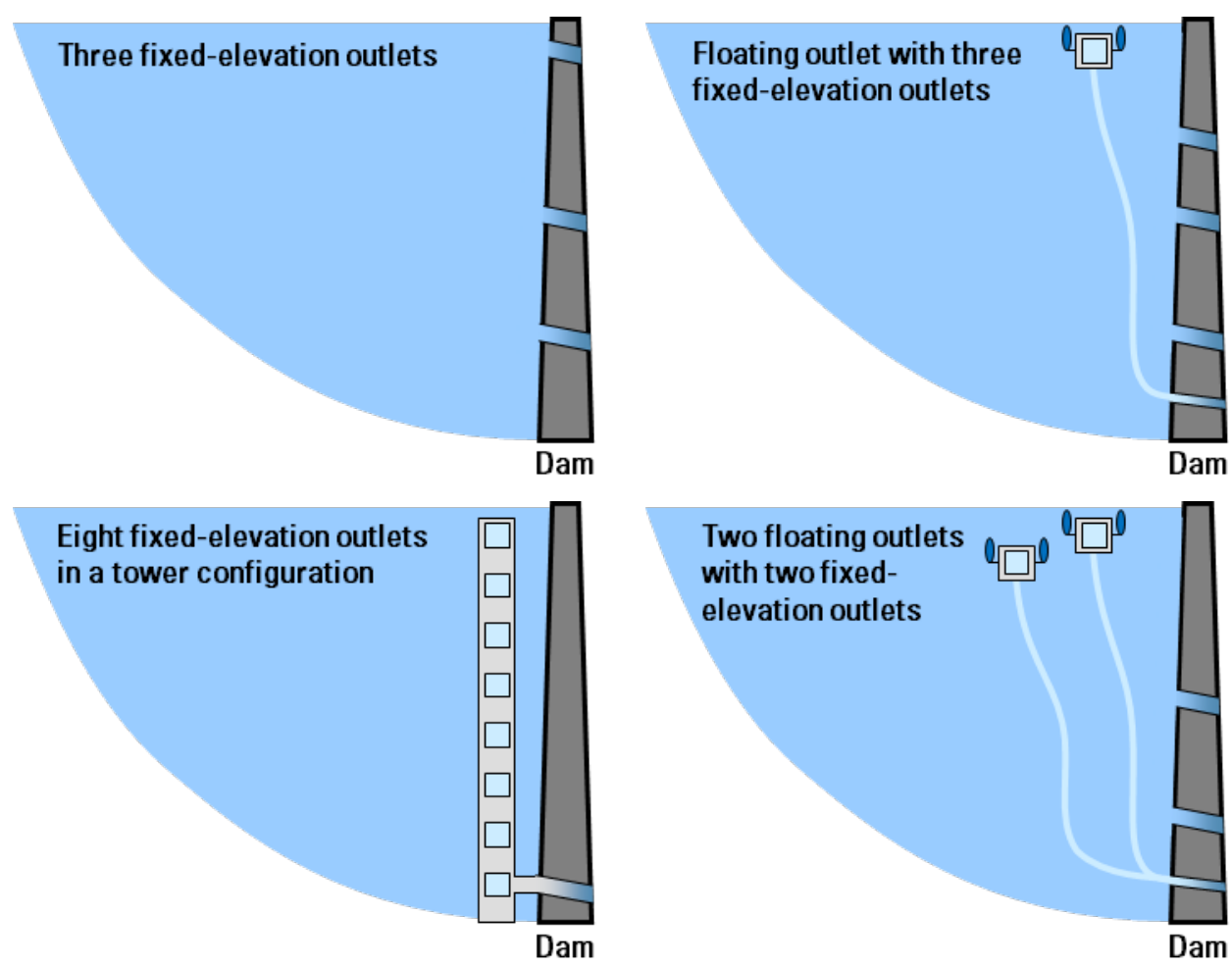

Figure 1. Example configurations of floating and fixed-elevation outlets that can be simulated by the modified model to blend releases to meet a downstream temperature target.

The modified blending algorithm implements a multi-step process that generally occurs as follows. First, the specified outlets are checked to see which ones are available for use - available outlets are those that are under water and meet any user-specified minimum and maximum head constraints. The temperature target for blended releases (those releases that the model is allowed to vary among available outlets) is determined after taking into account any nonblended releases (releases that the model must not modify). Priority designations are used to choose the outlets for blending, any minimum or maximum flow criteria are applied, and then the blending calculations are performed. The sections that follow describe the new user inputs, some checks for input errors, and the process for determining which outlets are used. Finally, descriptions of the blending algorithm, temperature targets, iterative solution technique, and allocation of releases to multiple outlets are provided. 


\section{New User-Specified Inputs}

All version 3.7 model inputs specifying the details of any temperature control devices and any groups of outlets to be blended are set in the w2_selective.npt input file. As in previous versions, the number of outlets and their general characteristics are still set in the w2_con.npt "control" file. In the w2 selective.npt file, two new inputs (TSFREQ, TSCONV) were added on the SPLIT1 input card. TSFREQ specifies the update frequency for the blending groups that are specified on the SPLIT2 input card, providing a means of separating the update frequency for blending groups and temperature control devices; previously, the update frequency was set for both algorithms with the TCDFREQ input. TSCONV specifies the convergence criterion for the blending calculations in units that correspond to the fraction of the total flow assigned to the first-priority outlets; therefore, TSCONV should be in the neighborhood of 0.1 or less, but nonzero. The default value for TSCONV is 0.005 .

Additional new inputs were added to the w2_selective.npt file, requiring some reformatting of that input file to accommodate the new blending inputs (see appendix 1). First, the maximum number of outlets in a blending group was increased from 2 to 10 . With only two outlets, the blending solution is straightforward, but requires the user to determine which outlets should be blended at any time in the simulation prior to running the model. With up to 10 outlets specified, other constraints are used to select the outlets to be used and how flows in those outlets are balanced. The choice of outlets is controlled largely through the user-specified "priority" input, which is described later (see section, "Using the Priority Input To Choose Outlets"). The following sections describe the new user-specified constraints, all of which are in the w2 selective.npt input file and summarized in table 1.

Dynamic Temperature Target (TSDYN on SPLIT2 input card).--Setting TSDYN to ON tells the model to override the temperature target (TTARGET) specified on the SPLIT2 input card and instead use a user-specified time-series of temperature targets from an external file named "dynsplit_selectiveX.npt" where X is the blending group number, starting at 1 . This is implemented in much the same way that the original version 3.7 code allowed the user to set a time series of temperature targets for the single-structure temperature control device. This change simply allows a similar functionality to be applied for the blending of releases from two or more outlets.

Depth (DEPTHx on the DEPTH input card).- - Specifying a nonzero depth for a particular outlet results in that outlet being treated as a floating outlet with a centerline elevation at DEPTH meters below the current water surface. This condition allows some outlets to be treated as floating outlets, an alternative to the original code that allowed one outlet to be "lowered" with the water surface if the ELCONT input was ON.

Minimum Head (MINHDx on the MINHEAD input card).-A nonzero minimum head criterion, specified for each blended outlet, is interpreted as the minimum depth in meters required for the outlet to be used. If the centerline outlet depth is shallower than this nonzero minimum head criterion, the outlet will not be used, regardless of any specified minimum flow criterion. This minimum head criterion is always honored. Inputs less than zero are changed to zero, which is interpreted as the absence of a minimum head criterion.

Maximum Head (MAXHDx on the MAXHEAD input card). - A nonzero maximum head criterion, specified for each blended outlet, is interpreted as the maximum depth in meters under which the outlet can be used. If the centerline outlet depth is deeper than this nonzero maximum head criterion, the outlet will not be used, regardless of any specified minimum flow criterion. This maximum head criterion is always honored. Inputs less than zero are changed to zero, which is interpreted as the absence of a maximum head criterion. 


\section{Table 1. Description of user-specified inputs in the w2_selective.npt file for blending.}

[For the code variables, the parentheses mean that the variable is an array, where $\mathrm{j}$ is the group number and $\mathrm{n}$ is the outlet number in that group.]

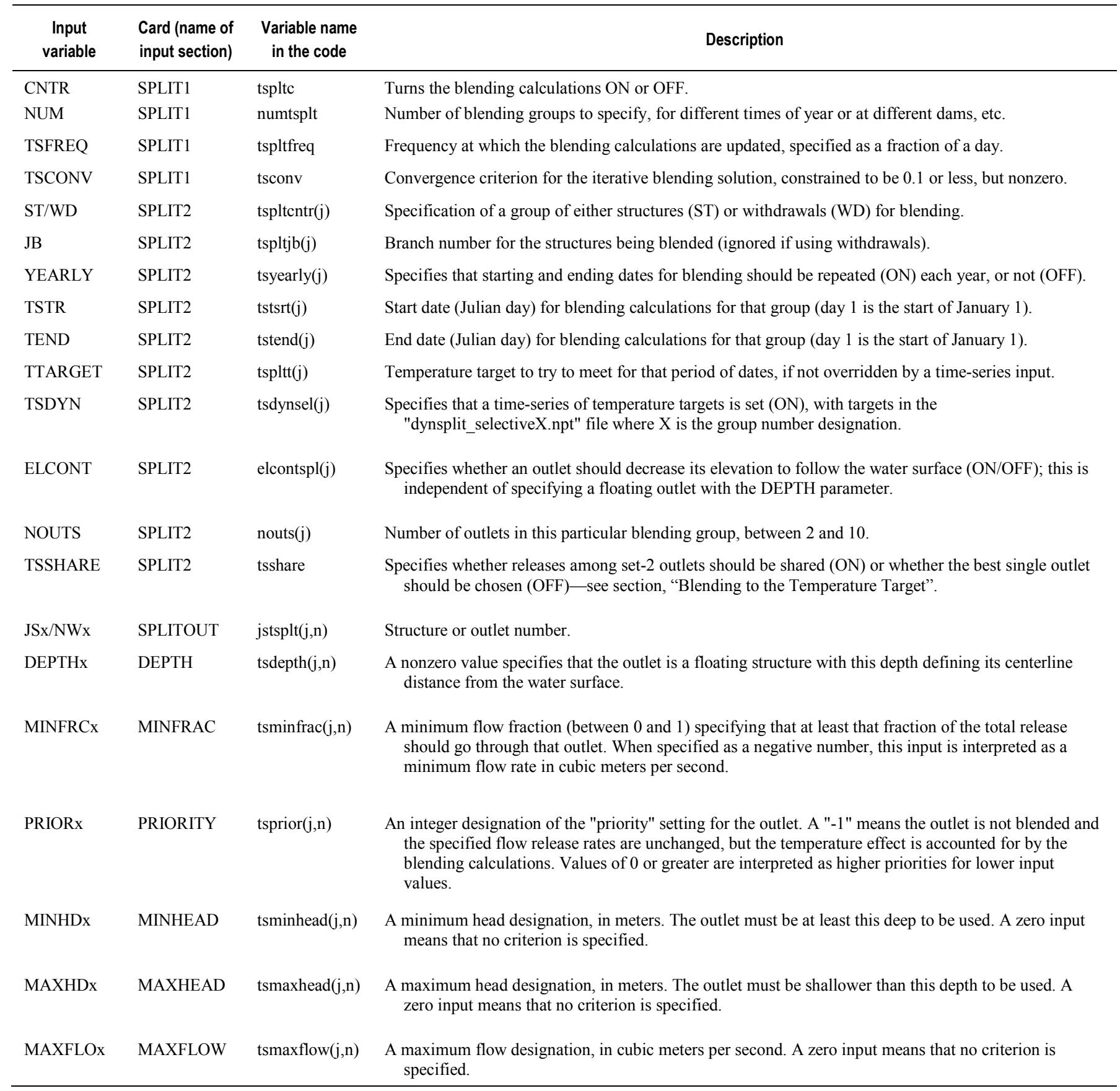


Maximum Flow (MAXFLOx on the MAXFLOW input card). - A nonzero maximum flow criterion, specified for each blended outlet in cubic meters per second, is honored regardless of its effect on temperature or any other minimum flow criterion. Inputs less than zero are changed to zero, which is interpreted as the absence of a maximum flow criterion.

Minimum Flow or Minimum Flow Fraction (MINFRCx on the MINFRAC input card). This input, specified for each outlet, can be used to specify a minimum flow rate or a minimum flow fraction. To specify a minimum flow rate, the input is negative and its absolute value is interpreted as a minimum flow rate in cubic meters per second. A minimum flow fraction is specified as a value between 0.0 and 1.0 and interpreted as the fraction of the total sum of all specified flows through outlets in the blending group. Values greater than 1.0 are set to 1.0. The blending algorithm attempts to honor all minimum flow criteria, but these criteria are subservient to the more important minimum head, maximum head, maximum flow, and priority inputs. If the priority is such that the outlet is not chosen to be used, the minimum flow criterion for that outlet is not honored. In addition, outlets that are high and dry (not under water) or that do not meet their minimum or maximum head criteria cannot have their minimum flows fulfilled.

Priority (PRIORx on the PRIORITY input card).- - The priority input is an integer limited to values of -1 or greater. The priority input is used to distinguish among groups of both blended and nonblended outlets and to choose which outlets to use at any time. The details of how this input is used to select outlets for blending are provided later in section, "Using the Priority Input To Choose Outlets".

Shared or Split Flows in Second Priority Group (TSSHARE on the SPLIT2 input card).When at least two outlets are members of the same priority group and are being used in a blending scheme to meet a user-specified temperature target, by default the flow assigned to the priority groups is distributed among the members of the group equally, but while still fulfilling the minimum and maximum flow criteria set by the user. The TSSHARE input allows this default behavior to be modified for the second (lower) priority group. When turned OFF, the blending algorithm attempts to find the one preferred member of the second priority group that can best be used in conjunction with the first priority group to meet the user-specified temperature target. Minimum and maximum flow criteria are still honored.

\section{Error Checks}

A number of checks for potential input errors were added to the SelectiveInit subroutine to ensure that user inputs do not lead to problems. Failure of any of the following error checks will cause the model run to terminate:

- At least 2 and no more than 10 outlets must be specified for the NOUTS input in each blending group on the SPLIT2 input card.

- Any single outlet can only be specified once in each blending group (SPLITOUT input card).

- Any single outlet can only be specified in one blending group or temperature control device at a time. (Start and end dates for each group are checked.)

- Integer priority specifications must be -1 or greater (PRIORITY input card). 


\section{Using the Priority Input To Choose Outlets}

The priority input is used to help choose which outlets are active and to put outlets into the two highest priority groups or "sets." Setting a priority of "-1" means that the outlet is NOT blended, but still taken into account for the purpose of meeting the user-defined temperature target. As long as the outlet is "wet" and the minimum and maximum head criteria are not violated, the originally specified flow for that nonblended outlet will be used, subject to a maximum flow limit. The flow and temperature of these nonblended outlets are taken into consideration when trying to match the temperature target for the entire blending group. This is a good way, therefore, to specify a flow for an outlet independent of blending, but still account for its effect on the total release temperature in blending calculations.

Priority inputs of 0 or larger are used to make decisions about which outlets in the blending group will be used. Lower priority numbers mean that the outlet has a higher priority for use; thus, an outlet with a priority of 1 has a higher priority than an outlet with a priority designation of 2 . The following describes the decision framework for determining which outlets are available, which will be used, and how they are assigned for use (see also the flow chart in fig. 2):

1. First, all outlets in the blending group (specified on the SPLITOUT input card) are assessed relative to the water surface. Non-floating outlets with a centerline elevation above the water surface are not used, regardless of other criteria. Outlets with a centerline elevation shallower than their specified minimum head criterion or deeper than their specified maximum head criterion are not used, regardless of other criteria.

2. Priority -1 (nonblended) outlets that are not ruled out in step 1 are used and given either their original user-specified flow rate or their maximum flow rate, whichever is lower.

3. The rest of the usable outlets are assessed relative to their priority designations. The two lowest ( 0 and greater) priority designations are determined and the outlets having those two priorities are counted and identified. The higher priority outlets (lowest priority input value) are put in "set A" and the next highest priority outlets are put in "set B." Any other outlets with lower priorities (greater priority input values) are not used, regardless of other criteria. Note that these priority inputs are a powerful means of specifying how a group of outlets can be used with a varying water-surface elevation, such as in a multiple-gate tower.

4. Minimum and maximum flow criteria are assessed for set A and B outlets. Any minimum flow criterion that exceeds a maximum flow criterion is reset so that the maximum flow criterion is not exceeded. The sum of the minimum (and maximum) flow fractions are computed for sets $\mathrm{A}$ and $\mathrm{B}$.

If minimum flow fractions are overspecified, meaning that the minimum flows from the nonblended outlets (priority: -1) and the set A and B outlets exceed the total flow of all outlets specified in the blending group, then the minimum flow fractions are decreased until the total flow is not exceeded. If minimum flow fractions need to be decreased, the set B minimum flows are decreased first, followed by those in set A. This can result in the elimination of all flow through set B outlets, or even the elimination of all flow through set A outlets as well. If minimum flow fractions are decreased, they are decreased in a percentage manner, such that an outlet with a large minimum flow fraction in set B would see a greater absolute decrease than another outlet in set B that started with a smaller minimum flow fraction. Obviously, the blending routines have more flexibility and power to meet the specified temperature target if they are not overly constrained by user-specified minimum flows. 


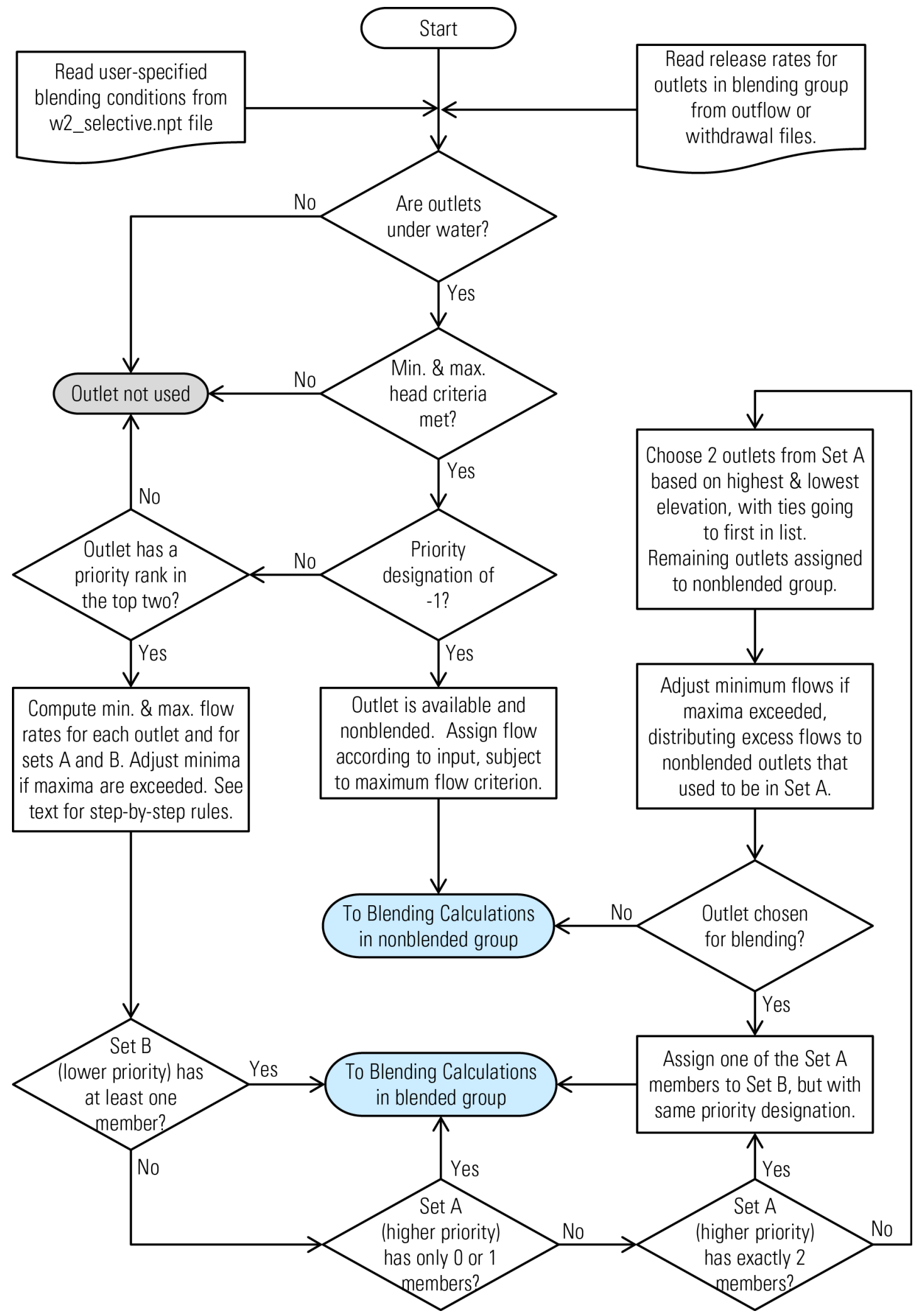

Figure 2. Flow chart for determining which outlets are available and used, and for assigning those outlets to the nonblended group, higher priority set $A$, and lower priority set $B$. 
5. Outlets are redistributed among priority sets, if necessary.

A. If set $\mathrm{B}$ has no members and set $\mathrm{A}$ has two members, then one of the members of set $\mathrm{A}$ is put into set $\mathrm{B}$, but retaining its set-A priority designation.

B. If set $B$ has no members and set $A$ has more than two members, then the algorithm needs more constraints to determine a solution. To provide that constraint, the algorithm chooses to blend between the highest- and lowest-elevation outlets in set A. If ties in elevation exist, then the first outlet with that elevation in the list is chosen. Any other outlets from set A are put in the nonblended group and assigned a flow equal to their minimum specified flow (which may be zero). If the two chosen outlets are constrained with maximum flows such that they cannot handle the total remaining flow available for blending, then that excess flow is distributed to the other (now nonblended) outlets that were originally in set A. That redistribution of flow is done equally, subject to maximum flow criteria. Finally, now that the number of outlets used for blending has been decreased to two, one of the remaining members of set $\mathrm{A}$ is put into set $\mathrm{B}$, but retaining its original priority designation.

At the end of step 5, sets A and B have at least one member and possibly more than one member. If only one or zero outlets are available, or if minimum flows comprise the entire release rate, then no blending is necessary and the solution is straightforward, but the temperature target is not likely to be met.

\section{Modified Blending Calculations}

At this point, all decisions have been made regarding which outlets to use. The next steps describe how the flows in each outlet are determined, in the following order:

1. If no usable outlets are available, then a message is written to the CE-QUAL-W2 warning file and all flows in the specified outlets are set to zero. This could happen if all outlets are high and dry or if they fail to meet their minimum or maximum head criteria.

2. If the only outlets are nonblended outlets, then a message is written to the warning file and the simulation proceeds without any blending calculations.

3. If only one blended outlet is available, then it receives all blended flow. If that blended flow exceeds the maximum flow criterion for that outlet, the flow in that outlet is decreased to its maximum flow and a message is written to the warning file.

4. If minimum flows comprise the entire release rate, then no blending calculations can be made, and all blended outlets are set to their minimum flows.

5. Finally, if more than one usable blended outlet is available and minimum flows do not take up all of the total flow, then blending calculations can occur!

Generally, flows are blended between two groups of outlets that may or may not have different priorities. The priority for set $\mathrm{A}$ is always equal to or higher (lower number) than the priority of set $\mathrm{B}$. If more than one outlet exists in set $\mathrm{A}$, then the overall flow assigned to that set is distributed equally to members of that set, subject to minimum and maximum flow criteria. If more than one outlet exists in set $\mathrm{B}$, then the TSSHARE (ON/OFF) input determines whether the overall flow assigned to set $\mathrm{B}$ is shared among the members of that set $(\mathrm{ON})$, or whether a preferred member of set $\mathrm{B}$ is identified to receive all non-minimum flows for that set (OFF). These calculations honor the minimum and maximum flow criteria for each individual outlet in sets A and B, with the goal of producing a combined release that comes as close as possible to the temperature target. 


\section{Temperature Target}

If nonblended releases are included in the user-specified blending group, the temperatures of those nonblended releases are estimated, weighted by their flow rates, and used to determine a modified temperature target for the blended outlets. The modified temperature target is:

$$
\mathrm{T}_{\mathrm{bl}}=\frac{\mathrm{T}_{\text {orig }}-\mathrm{F}_{\mathrm{nb}} \mathrm{T}_{\mathrm{nb}}}{1.0-\mathrm{F}_{\mathrm{nb}}},
$$

where $\mathrm{T}_{\mathrm{bl}}$ is the new temperature target for blended releases,

$\mathrm{T}_{\text {orig }}$ is the original temperature target for the total release,

$\mathrm{T}_{\mathrm{nb}}$ is the estimated release temperature of all nonblended flows, and

$F_{n b}$ is the fraction of the total release accounted for by nonblended releases.

\section{Iterative Solution and Convergence}

Each time the blending subroutine of the model is called, blending calculations for that date and time are done in an iterative fashion (see the flow chart in fig. 3). An iterative solution is required because the flow rate through an outlet affects the temperature of the water released through that outlet. The selective withdrawal algorithm in the model dictates that larger release flows draw from a wider range of depths (more layers) in the reservoir water column, thereby mixing waters of potentially different temperatures for release (Cole and Wells, 2011). In contrast, smaller release flows draw from a narrower range of depths and thereby mix temperatures from fewer layers. The blending calculations allow a maximum of eight iterations, and convergence is measured by comparing the fraction of total flow assigned to set $\mathrm{A}$ in the current iteration to the same quantity from the previous iteration. If the two values agree within the user-specified convergence criterion of TSCONV, or if the total flow is zero, or if the maximum number of iterations has occurred, then the loop is terminated. Using an iterative solution causes model run times to increase, but produces a more accurate blending solution; shorter run times are likely with a less-stringent convergence criterion (larger TSCONV, value constrained $\leq 0.1$ and $>0.0$ ), but the time savings may not be significant on a fast computer.

It is possible for the blending calculations to not converge within eight iterations. If that happens, a message is written to the warning file. When two blended outlets are similar in elevation, it sometimes occurs that the iterative solution is unstable, with large flow fractions moving back and forth between sets A and B with each iteration. The blending algorithm tests for such an unstable solution and assigns the flow fractions in that case based on set priority. If the sets have identical priorities, then the non-minimum flows are split equally among the two sets.

\section{Blending to the Temperature Target}

For the first iteration of the blending calculations, initial flow rates for each blended outlet are set by applying the various minimum and maximum flow constraints and dividing the rest of the available flow equally among sets $\mathrm{A}$ and $\mathrm{B}$. The flows assigned to individual outlets in each set are based on the total flow for the set, the various minimum and maximum flow criteria, and a rule governing equal or split distributions. In set $\mathrm{A}$, and in set $\mathrm{B}$ under shared flows (TSSHARE $=\mathrm{ON}$ ), releases are distributed equally to all outlets in the set after first fulfilling the minimum flow requirements of each outlet. Honoring the maximum flow criteria then may require some redistribution of flows to other outlets in the set that have not exceeded their maximum flow criteria. For example, if set A has three outlets, is assigned 30 percent of the total flow, and none of the outlets in set A have 


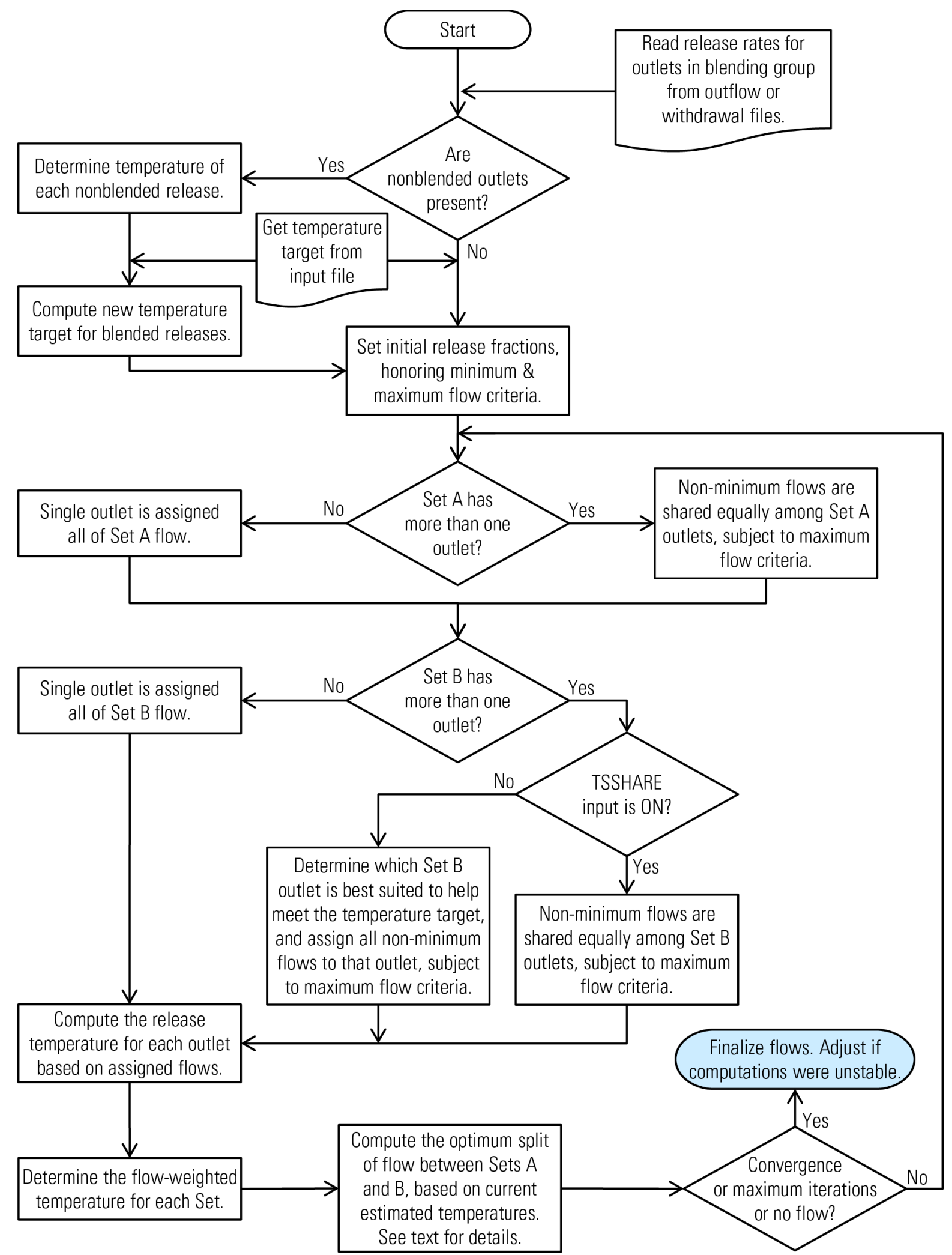

Figure 3. Flow chart for determining the temperature target, allocating flows among the outlets in sets $A$ and $B$, and iterating to converge to an optimum blending solution that best meets the temperature target. 
minimum or maximum flow criteria, then each outlet in set A will be assigned 10 percent of the total release. However, if one of the three outlets has a minimum flow fraction of 6 percent, then the remaining 24 percent is divided up three ways, resulting in two outlets with 8 percent of the flow and the one with the minimum flow fraction receiving 14 percent. In set B, the flows are distributed among the members of that set in the same way as for set A as long as the TSSHARE input is ON. If TSSHARE is OFF, then flows are assigned to a preferred outlet in set $\mathrm{B}$, while also honoring the minimum and maximum flow criteria for outlets in that set. The preferred outlet is the single outlet in set B that appears to have the greatest potential for helping to meet the overall temperature target based on either its elevation or estimated release temperature.

The initial release temperature for each outlet is calculated based on its initial flow. The total mixed estimated temperature for each set then is computed as the flow-weighted temperature of its member outlets. The next iteration of the blending calculation proceeds based on the estimated temperatures produced from the previous iteration, as described in the following paragraphs.

If the target blend temperature is less than the total mixed estimated release temperatures from both sets $\mathrm{A}$ and $\mathrm{B}$, then the set producing the lowest temperature is assigned the blended flow, subject to the minimum flow requirements of all outlets. If the sets are producing more or less identical temperatures (within $0.001{ }^{\circ} \mathrm{C}$ ), then the highest priority set gets more of the flow, subject to minimum flow requirements. If release temperatures are the same and sets A and B have identical priorities, then the set with the lower flow-weighted elevation gets the non-minimum flows.

Similarly, if the target blend temperature is greater than the total mixed estimated release temperatures from both sets $\mathrm{A}$ and $\mathrm{B}$, then the set producing the highest temperature is assigned the blended flow, subject to the minimum flow requirements of all outlets. If the sets are producing more or less identical temperatures (within $0.001{ }^{\circ} \mathrm{C}$ ), then the highest priority set gets more of the flow, subject to minimum flow requirements. If release temperatures are the same and sets $\mathrm{A}$ and $\mathrm{B}$ have identical priorities, then the set with the higher flow-weighted elevation gets the non-minimum flows.

If the target blend temperature is essentially the same as the two mixed estimated release temperatures from sets $\mathrm{A}$ and $\mathrm{B}$, then the set with the higher priority is assigned the blended flow, subject to the minimum flow requirements of all outlets. If sets A and B have identical priorities, then the non-minimum flows are split equally among the two sets.

If the target blend temperature is between the mixed estimated release temperatures of the two sets, then the blended flows are split among the two sets of outlets in an attempt to match the target temperature, using the following equation:

$$
F_{A}=\left(1.0-F_{n b}\right) \text { abs }\left(\frac{T_{b l}-T_{B}}{T_{A}-T_{B}+10^{-20}}\right) \text {, }
$$

where $\quad \mathrm{F}_{\mathrm{A}} \quad$ is the fraction of the total release assigned to set $\mathrm{A}$ in the next iteration,

$\mathrm{F}_{\mathrm{nb}} \quad$ is the fraction of the total release accounted for by nonblended releases,

$\mathrm{T}_{\mathrm{bl}} \quad$ is the temperature target for blended releases,

$\mathrm{T}_{\mathrm{A}} \quad$ is the estimated temperature of releases from set $\mathrm{A}$,

$\mathrm{T}_{\mathrm{B}} \quad$ is the estimated temperature of releases from set $\mathrm{B}$,

abs is the absolute value function, and

the $10^{-20}$ value is present to guard against divide-by-zero errors in the program.

The value of $\mathrm{F}_{\mathrm{A}}$ is constrained to be between 0.0 and 1.0. The fraction of the total release assigned to set $\mathrm{B}$ in the next iteration, then, is computed as $1.0-\mathrm{F}_{\mathrm{nb}}-\mathrm{F}_{\mathrm{A}}$. After this calculation is completed, the minimum and maximum flow criteria are again applied to constrain the calculated set-specific release fractions, and the computations loop to the next iteration to search for convergence. 


\section{Other Details in the Blending Algorithm}

A number of other details in the modified blending algorithm were designed to keep the calculations robust under a wide variety of imposed conditions. For example, when the total flow in a blended group is zero but becomes nonzero soon after, such as during power-peaking releases, the flow fractions that would be assigned to the outlets under zero-flow conditions are sometimes not appropriate for when the flows become nonzero again, which could lead to spikes in the release temperature if the flow fractions were not recalculated immediately upon the change in release conditions. In this case, it was deemed best to NOT recalculate the flow fractions, but use the flow fractions from a previous nonzero flow assignment. Tests were put in place to ensure that the calculations are performed when a new control period is first entered or when the flow fractions are uninitialized, even if the total flow release is zero. For these and other details of the code implementation, readers can scan the model code in the withdrawal.f90 source file (see section, "Supplementary Material").

\section{Examples to Illustrate New Capabilities}

Five examples are included in this section to illustrate how combinations of the new userspecified constraints and priority designations can be used to control how the model assigns flow releases to combinations of outlets in a way that efficiently accomplishes certain objectives with a minimum of user intervention. Each example includes a short description, a diagram of the dam outlets, a list of user-specified constraints, and the relevant part of the w2_selective.npt file showing how to format the user inputs. Full copies of the w2_selective.npt input files are included in appendix 1.

\section{Example 1: Power Production Shared with Spillway or Regulating Outlet}

A relatively simple, but useful, example implementing the new blending code uses three fixedelevation dam outlets to meet a downstream temperature target by switching between a near-surface spillway and a deep regulating outlet $(\mathrm{RO})$ to blend releases with a medium-depth hydropower outlet (fig. 4). In this case, the emphasis was on power generation, so the power outlet was given a 40 percent minimum flow criterion (MINFRAC $=0.4$ ). To blend the power releases with either the spillway or the $\mathrm{RO}$, but not both, the power outlet was given a priority of 1, the spillway and RO were given priorities of 2 , and the TSSHARE input was set to OFF. In this way, the model will choose either the spillway or the RO to blend releases with the power outlet, but will never use the spillway and the RO at the same time. As an additional constraint, the RO cannot be used if it is deeper than $50 \mathrm{~m}$. In this example, that likely means that when the lake is full, the RO cannot be used, but the spillway is available. In contrast, when the lake is not full, the water level may be below the spillway crest elevation, causing that outlet to be unavailable. When both the spillway and the RO are available, however, the model will test the temperature releases from both and choose the one that is best suited, in combination with the power outlet, to meet the user-specified target release temperature. 


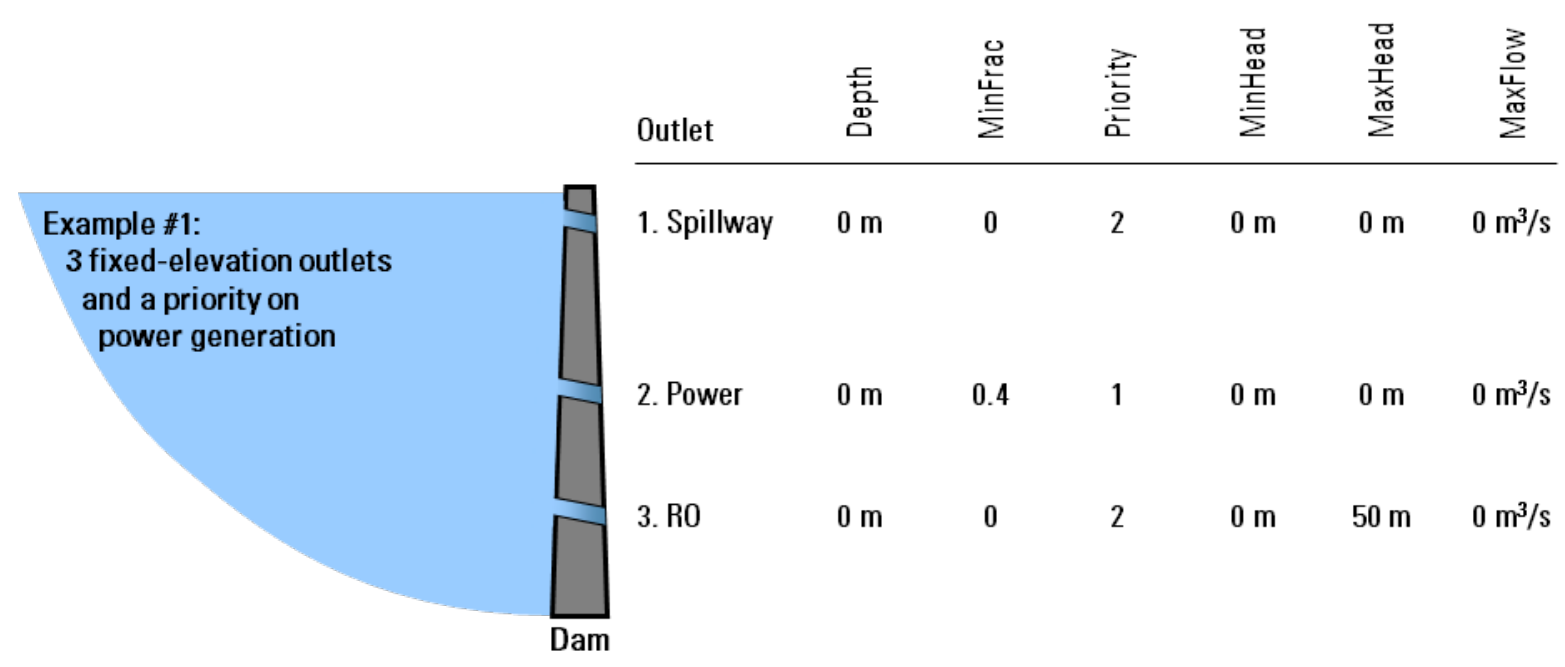

The relevant portion of the w2_selective.npt file is as follows:

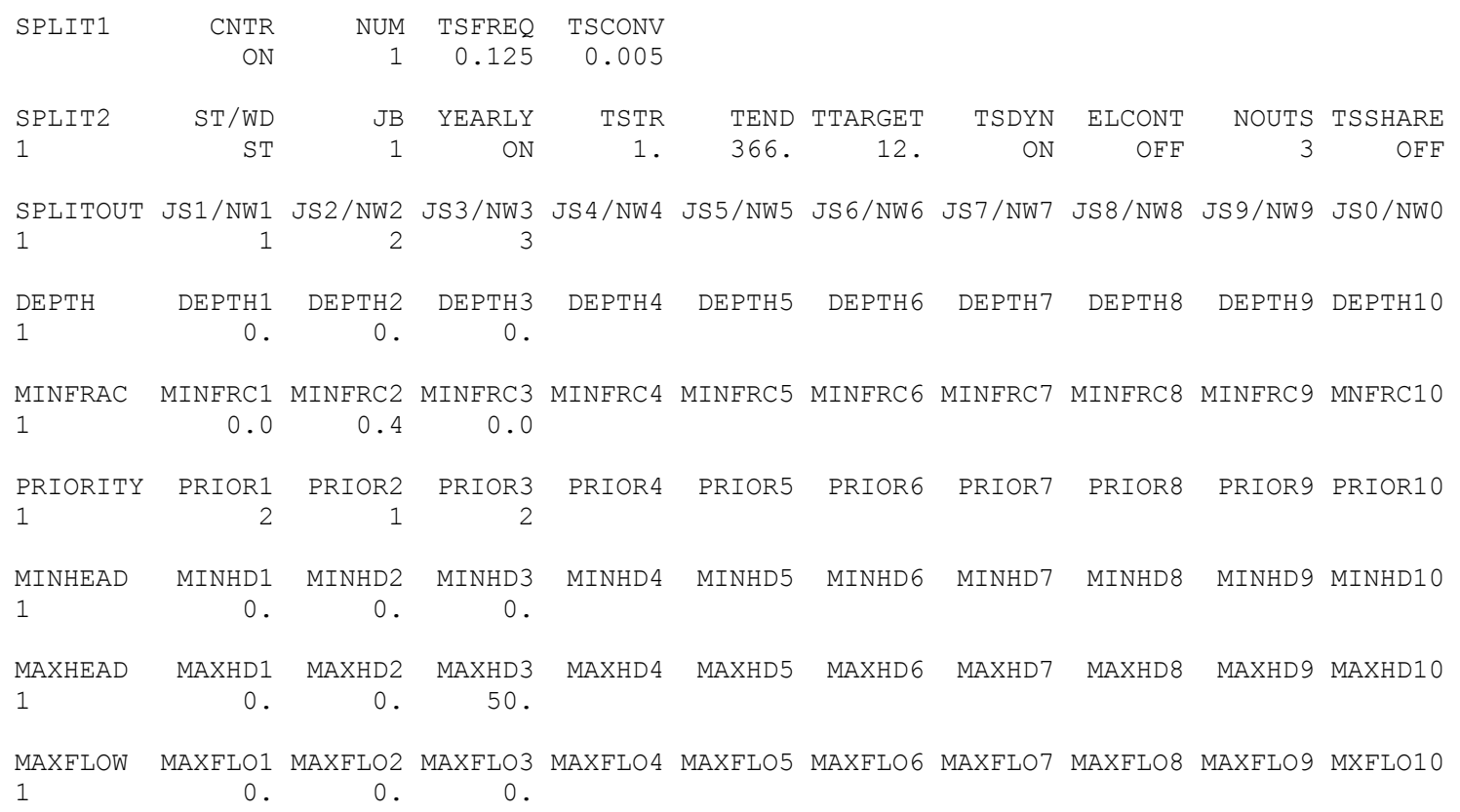

Figure 4. Example 1 uses three fixed-elevation outlets, in which the power outlet has the highest priority and is assigned at least 40 percent of the total release, and the regulating outlet (RO) has a maximum head constraint of 50 meters. Using a TSSHARE = OFF condition, the model must choose either the spillway or the RO to blend releases with the power outlet. 


\section{Example 2: Floating and Fixed Outlets with a Nonblended Release}

In this example, a floating outlet and a deep regulating outlet (RO) are blended with releases from a mid-depth hydropower outlet (fig. 5). This example is more complicated and has more constraints and intricacies than the first example. First, a nonblended release is included, invoked by a "-1" priority designation. Release rates are not modified for nonblended outlets, but are taken directly from the user input time-series files. Nonblended releases are accounted for in the blending calculations, however, in terms of their effect on the total flow-weighted release temperature from all outlets in the group. The model determines the temperature released from the nonblended outlet, then adjusts the userspecified temperature target to create a new target temperature for the remaining, blended releases.

The first outlet is treated as a floating outlet because a nonzero depth is specified by the user. In this case, the outlet's centerline elevation will always be $2.3 \mathrm{~m}$ below the water surface. The floating outlet also has a minimum flow specification of $11.3 \mathrm{~m}^{3} / \mathrm{s}$; the negative input for MINFRAC is interpreted as a flow rate in cubic meters per second rather than a minimum flow fraction. In contrast, the power outlet has a MINFRAC of 0.2 , meaning that at least 20 percent of the releases should go through the power outlet. The RO has a maximum head criterion of $50 \mathrm{~m}$, meaning that it cannot be used if its centerline elevation is deeper than that depth. Several of the outlets have maximum flow constraints, such that excess flow would be diverted by the model to other nonblended outlets.

The goal in this example was to blend non-minimum releases between the power outlet and either the floating outlet or the RO. Therefore, the power outlet was given a priority of 1 , the TSSHARE input was set to OFF, and the priority for the floating outlet and the RO was set to 2 . The results are more complex than in the first example, however, because a minimum flow was specified for the floating outlet. When the temperature target is warmer than temperatures being released by the power outlet, the model may choose to use the floating outlet, but a minimum flow already is being released by the floating outlet. The model will try to find the optimum blend of releases from the power and floating outlets to meet the temperature target, but also ensuring that minimum flows through each are fulfilled. Later in the year, if the temperature target is cooler than releases that can be obtained through the power outlet, the model will try to release cooler water through the RO. In that case, blending occurs between the power outlet and the RO, but minimum flows through the floating outlet also occur because of its minimum flow specification. Passing a minimum amount of water through a floating outlet, even when it does not help to meet a downstream release temperature, might be important for other goals, such as downstream fish passage. 


\begin{tabular}{|c|c|c|c|c|c|c|c|}
\hline & Outlet & $\begin{array}{l}\text { 동 } \\
\text { 吾 }\end{array}$ & 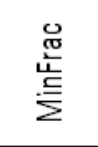 & 紊 & 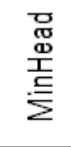 & 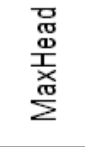 & $\begin{array}{l}\frac{z}{3} \\
\frac{0}{1} \\
\frac{x}{\Sigma} \\
\sum\end{array}$ \\
\hline \multirow{4}{*}{$\begin{array}{l}\text { Example \#2: } \\
\text { Floating outlet blended } \\
\text { with two fixed-elevation } \\
\text { outlets, and including a } \\
\text { nonblended outlet }\end{array}$} & 1. Floating & $2.3 \mathrm{~m}$ & -11.3 & 2 & $0 \mathrm{~m}$ & $0 \mathrm{~m}$ & $150 \mathrm{~m}^{3} / \mathrm{s}$ \\
\hline & 2. Nonblended & $0 \mathrm{~m}$ & 0 & -1 & $0 \mathrm{~m}$ & $0 \mathrm{~m}$ & $0 \mathrm{~m}^{3} / \mathrm{s}$ \\
\hline & 3. Power & $0 \mathrm{~m}$ & 0.2 & 1 & $0 \mathrm{~m}$ & $0 \mathrm{~m}$ & $150 \mathrm{~m}^{3} / \mathrm{s}$ \\
\hline & 4. R0 & $0 \mathrm{~m}$ & 0 & 2 & $0 \mathrm{~m}$ & $50 \mathrm{~m}$ & $150 \mathrm{~m}^{3} / \mathrm{s}$ \\
\hline
\end{tabular}

The relevant portion of the w2_selective.npt file is as follows:

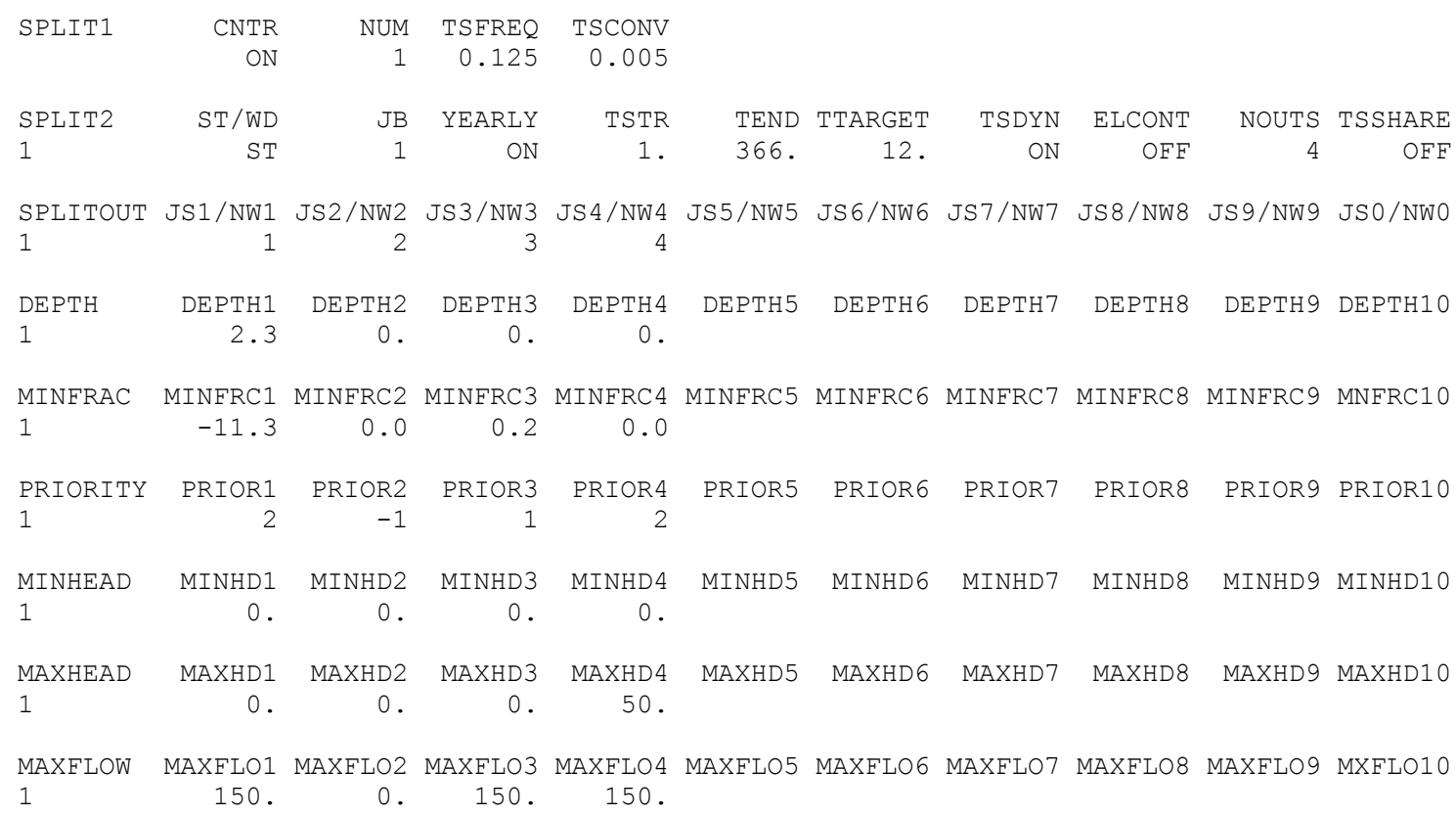

Figure 5. Example 2 uses a nonblended outlet (priority -1 ) and blends the remaining releases among a floating outlet and two fixed-elevation outlets. The power outlet has the highest priority and is assigned at least 20 percent of the total release. The floating outlet is assigned a flow of at least $11.3 \mathrm{~m}^{3} / \mathrm{s}$, and the regulating outlet (RO) has a maximum head constraint of 50 meters. Several outlets are subject to maximum flow constraints of $150 \mathrm{~m}^{3} / \mathrm{s}$. Using a TSSHARE = OFF condition, and after first fulfiling the minimum flow constraints, the model must choose either the spillway or the $\mathrm{RO}$ to blend non-minimum releases with releases from the power outlet. The final releases also must honor the maximum flow constraints by shifting any excess flow to other outlets. 


\section{Example 3: Eight Fixed Gates with Ranked Priorities}

This example uses a tower assembly of eight fixed-elevation gates and an ordered set of priority settings to ensure that cold water from deep in the lake is blended with presumably warmer water near the surface of the lake (fig. 6). Few constraints are placed on the outlets - each has a minimum head criterion, which requires the centerline elevation of each outlet to be at least $2 \mathrm{~m}$ below the water surface for the outlet to be used. In recognition that the water-surface elevation of the lake is likely to be variable over the course of the year, the deepest outlet is assigned a priority of 1 and the remaining outlets are assigned priorities of 2 to 8 in order from top to bottom.

The model always will choose to blend releases from outlets with the top two priority designations, where lower priority designations are interpreted as higher priorities for use ( 1 is a higher priority than 2). Using the priority assignment scheme in this example, when the lake is drawn down and outlets 1 through 3 are above the water surface, the model will blend releases from outlet 4 (priority 5 , near surface) and outlet 8 (priority 1 , near bottom) because they have the highest available priorities. Note that neither has a minimum flow criterion, so it is entirely possible, depending on the temperature target and the temperature structure of the lake, that one of those outlets will be assigned the entire release rate for the group. The other outlets that are available (deeper than their minimum head criterion) all have lower priorities (higher priority input values) than these two outlets, and therefore will not be used.

This scheme ensures that cold water from the bottom of the lake will be blended with water from near the surface of the lake in an attempt to meet the downstream temperature target. The scheme might not work well, however, if a maximum head criterion were added for the outlet near the bottom of the lake. In that case, if the outlet were deeper than its maximum head criterion, it would not be used and the model would blend releases between two adjacent gates near the water surface (because of their priority designations) and probably would fail to meet the objectives of the model run. When few other constraints are needed, however, this sort of priority designation scheme might be useful. 


\begin{tabular}{|c|c|c|c|c|c|c|c|c|}
\hline & & Outlet & $\begin{array}{l}\text { 吉 } \\
\text { 号 }\end{array}$ & 旁 & :흔 & 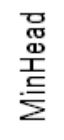 & 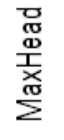 & 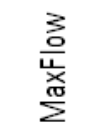 \\
\hline \multirow{8}{*}{$\begin{array}{l}\text { Example \#3: } \\
\text { Eight fixed-elevation gates } \\
\text { with ranked priorities }\end{array}$} & $\square$ & 1. Fixed & $0 \mathrm{~m}$ & 0 & 2 & $2 m$ & $0 \mathrm{~m}$ & $0 \mathrm{~m}^{3} / \mathrm{s}$ \\
\hline & $\square$ & 2. Fixed & $0 \mathrm{~m}$ & 0 & 3 & $2 \mathrm{~m}$ & $0 \mathrm{~m}$ & $0 \mathrm{~m}^{3} / \mathrm{s}$ \\
\hline & $\square$ & 3. Fixed & $0 \mathrm{~m}$ & 0 & 4 & $2 m$ & $0 \mathrm{~m}$ & $0 \mathrm{~m}^{3} / \mathrm{s}$ \\
\hline & $\square$ & 4. Fixed & $0 \mathrm{~m}$ & 0 & 5 & $2 m$ & $0 \mathrm{~m}$ & $0 \mathrm{~m}^{3} / \mathrm{s}$ \\
\hline & $\square$ & 5. Fixed & $0 \mathrm{~m}$ & 0 & 6 & $2 m$ & $0 \mathrm{~m}$ & $0 \mathrm{~m}^{3} / \mathrm{s}$ \\
\hline & $\square$ & 6. Fixed & $0 \mathrm{~m}$ & 0 & 7 & $2 m$ & $0 \mathrm{~m}$ & $0 \mathrm{~m}^{3} / \mathrm{s}$ \\
\hline & $\square$ & 7. Fixed & $0 \mathrm{~m}$ & 0 & 8 & $2 \mathrm{~m}$ & $0 \mathrm{~m}$ & $0 \mathrm{~m}^{3} / \mathrm{s}$ \\
\hline & $\square^{L}$ & 8. Fixed & $0 \mathrm{~m}$ & 0 & 1 & $2 m$ & $0 \mathrm{~m}$ & $0 \mathrm{~m}^{3} / \mathrm{s}$ \\
\hline
\end{tabular}

The relevant portion of the w2_selective.npt file is as follows:

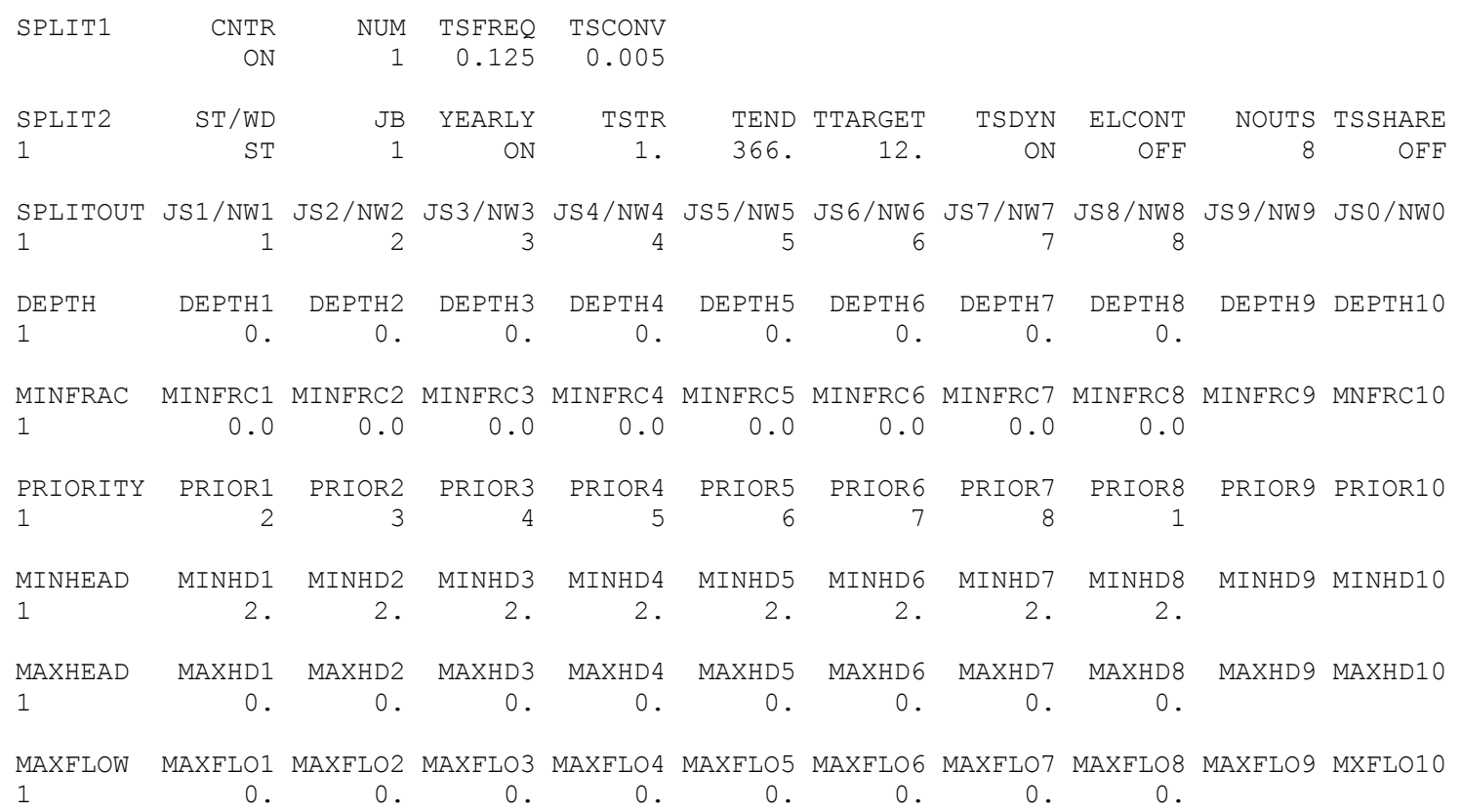

Figure 6. Example 3 uses a tower of eight fixed-elevation gates, in which the priorities are assigned to ensure that releases are blended between the lowest outlet (highest priority of 1 ) and the highest available outlet. In this example, an outlet's centerline elevation must be at least 2 meters below the water surface to be available for use, as specified by the minimum head criteria. 


\section{Example 4: Eight Fixed Gates with Identical Priorities}

In contrast to the previous example in which each of the eight fixed-elevation outlets was given a different priority in an attempt to control the model's choice of outlets, this example shows that a similar objective might be achieved by setting the same priority for all outlets (fig. 7). The same eight fixedelevation outlets are used, but this time with both minimum and maximum head constraints. With a maximum head constraint, the deepest outlets might not be available when the lake is full, which might cause a ranked priority scheme to fail. To complicate things a bit further, this example includes the specification that at least 20 percent of the total release (MINFRAC $=0.2$ ) should be routed through outlet 6 , if that outlet is available for use.

Using identical priorities for all outlets, the model will attempt to choose two outlets from among all available outlets to blend the non-minimum releases. To illustrate, suppose that the lake is relatively full, and the model determines that outlets 2 through 7 are available after checking their depths against the minimum and maximum head constraints. In a case with many outlets having the same priority, the model would choose the two available outlets with the highest and lowest elevations for blending the non-minimum releases. Therefore, outlets 2 and 7 would be used to blend the nonminimum releases, and outlet 6 would receive its minimum flow of 20 percent of the total release rate. If the lake level were higher still and outlets 1 through 6 were available, then blending would occur between outlets 1 and 6 , but ensuring that outlet 6 received at least 20 percent of the total release. If, however, only outlets 1 through 5 were available, then outlet 6 would not be used at all, forfeiting its minimum release because its maximum head criterion must be honored.

This method of using identical priority designations clearly can work well if the objective is simply to blend water from shallow and deep outlets in a lake. This method fails, however, to allow one particular outlet to be used more than the others. For example, if increased releases through outlet 6 were desirable for some reason, that outlet could be given a higher priority (say 1, with all other outlets assigned a priority of 2). If the TSSHARE input is OFF, then releases through outlet 6 would be blended with releases from either near the water surface or near the lake bottom, depending on the value of the temperature target. If outlet 6 were not available at some point, however, the remaining outlets would all have the same priority and the model would proceed as previously described for a set of outlets having the same priority. 


\begin{tabular}{|c|c|c|c|c|c|c|c|c|}
\hline & & Outlet & $\begin{array}{l}\text { 吉 } \\
\text { 号 }\end{array}$ & 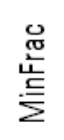 & :흔 & 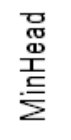 & 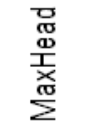 & 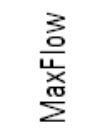 \\
\hline \multirow{8}{*}{$\begin{array}{l}\text { Example \#4: } \\
\text { Eight fixed-elevation gates } \\
\text { with identical priorities } \\
\text { and some depth and } \\
\text { flow constraints }\end{array}$} & $\square$ & 1. Fixed & $0 \mathrm{~m}$ & 0 & 1 & $3 \mathrm{~m}$ & $50 \mathrm{~m}$ & $0 \mathrm{~m}^{3} / \mathrm{s}$ \\
\hline & $\square$ & 2. Fixed & $0 \mathrm{~m}$ & 0 & 1 & $3 \mathrm{~m}$ & $50 \mathrm{~m}$ & $0 \mathrm{~m}^{3} / \mathrm{s}$ \\
\hline & $\square$ & 3. Fixed & $0 \mathrm{~m}$ & 0 & 1 & $3 \mathrm{~m}$ & $50 \mathrm{~m}$ & $0 \mathrm{~m}^{3} / \mathrm{s}$ \\
\hline & $\square$ & 4. Fixed & $0 \mathrm{~m}$ & 0 & 1 & $3 \mathrm{~m}$ & $50 \mathrm{~m}$ & $0 \mathrm{~m}^{3} / \mathrm{s}$ \\
\hline & $\square$ & 5. Fixed & $0 \mathrm{~m}$ & 0 & 1 & $3 \mathrm{~m}$ & $50 \mathrm{~m}$ & $0 \mathrm{~m}^{3} / \mathrm{s}$ \\
\hline & $\square$ & 6. Fixed & $0 \mathrm{~m}$ & 0.2 & 1 & $3 \mathrm{~m}$ & $50 \mathrm{~m}$ & $0 \mathrm{~m}^{3} / \mathrm{s}$ \\
\hline & $\square$ & 7. Fixed & $0 \mathrm{~m}$ & 0 & 1 & $3 \mathrm{~m}$ & $50 \mathrm{~m}$ & $0 \mathrm{~m}^{3} / \mathrm{s}$ \\
\hline & & 8. Fixed & $0 \mathrm{~m}$ & 0 & 1 & $3 \mathrm{~m}$ & $50 \mathrm{~m}$ & $0 \mathrm{~m}^{3} / \mathrm{s}$ \\
\hline
\end{tabular}

The relevant portion of the w2_selective.npt file is as follows:

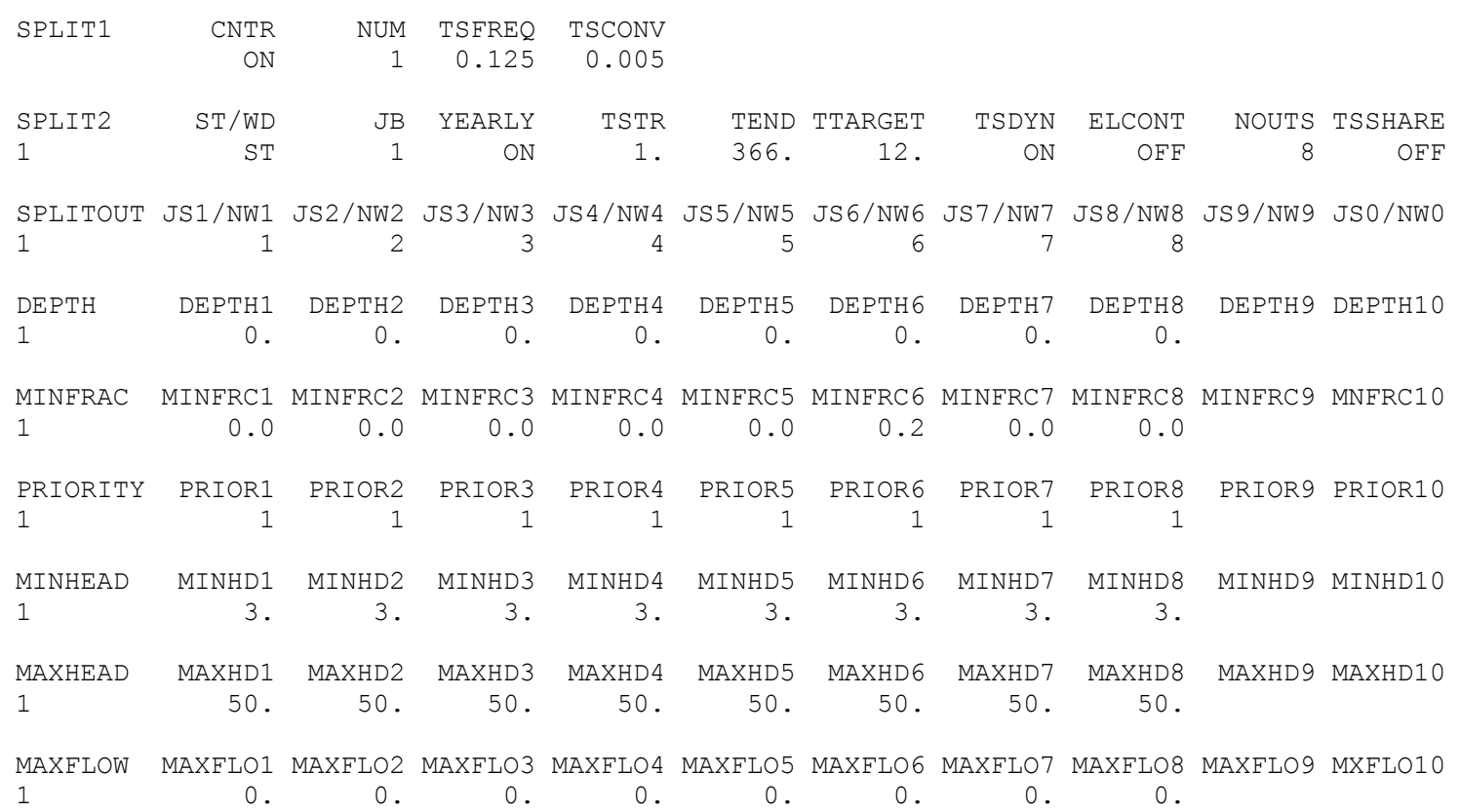

Figure 7. Example 4 uses a tower of eight fixed-elevation gates, in which the priorities are all identical. To be available for use, each outlet's centerline elevation must be at least 3 meters and less than 50 meters below the water surface. With identical priorities, the model will blend releases between the highest and lowest available outlets, after first fulfilling any minimum flow requirements. In this example, at least 20 percent of the total release must be routed through gate number 6 , if it is available for use. 


\section{Example 5: Shared Floating Outlets with a Schedule}

This example illustrates the effects of turning the TSSHARE input ON and using more than one blending group to change the outlets used for blending partway through a model run. In this case, two floating outlets are specified along with two fixed-elevation outlets, and a schedule is used to blend releases from the floating outlets with just one of the fixed-elevation outlets at a time (fig. 8). Not only are the fixed-elevation outlets set at different depths (in the w2_con.npt control file), but the floating outlets also are given different depths using the depth input in the w2_selective.npt file. Minimum and maximum flow criteria are specified for all outlets.

To blend releases from the floating outlets with different fixed-elevation outlets at different times of the year, a schedule can be set up by specifying two blending groups (NUM=2 on the SPLIT1 input card) with different starting and ending dates (TSTR and TEND on the SPLIT2 input card). Then, each group can be configured with three outlets for blending (NOUTS=3 on the SPLIT2 input card), and specifying outlets 1,2, and 3 for the first group and 1, 2, and 4 for the second group (on the SPLOTOUT input card). In this way, the floating outlets are blended with the medium-depth fixed outlet for part of the year and with the deeper fixed outlet for the rest of the year. Note that the simplest way to set up the outflow boundary file is to assign the total release rate to the first outlet. That way, when outlet 4 is not used for the first period of the run, a release rate of zero will be used for that outlet. Similarly, outlet 3 will have a zero release rate when it is not being blended with outlets 1 and 2 later in the year.

One way to ensure that releases through each of the floating outlets are identical, despite their different depths, is to specify that releases in the lower priority group are shared (TSSHARE $=\mathrm{ON}$ ), and specify a priority of 2 for the floating outlets and a priority of 1 for the fixed-elevation outlets. All these outlets have minimum flow specifications (at least $5.66 \mathrm{~m}^{3} / \mathrm{s}$ for each of the floating outlets, and at least 20 percent of the flow to the fixed-elevation outlet). After fulfilling those minimum flows, any nonminimum releases will be blended between a single fixed-elevation outlet (set A) and the two floating outlets (set B). The model honors the maximum flow constraints at all times, and honors the minimum flow constraints when sufficient releases are available. If insufficient releases are available to honor the minimum flow constraints, then releases are scaled back in the lower priority group first. 


\begin{tabular}{|c|c|c|c|c|c|c|c|}
\hline & Outlet & 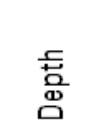 & 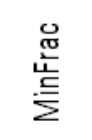 & 妾 & 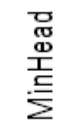 & 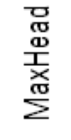 & 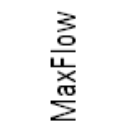 \\
\hline \multirow{3}{*}{$\begin{array}{l}\text { Example 5: } \\
\text { Two floating outlets } \\
\text { with two fixed- } \\
\text { elevation outlets }\end{array}$} & $\begin{array}{l}\text { 1. Floating } \\
\text { 2. Floating }\end{array}$ & $\begin{array}{l}3.0 \mathrm{~m} \\
7.5 \mathrm{~m}\end{array}$ & $\begin{array}{l}-5.66 \\
-5.66\end{array}$ & $\begin{array}{l}2 \\
2\end{array}$ & $\begin{array}{l}0 \mathrm{~m} \\
0 \mathrm{~m}\end{array}$ & $\begin{array}{l}0 \mathrm{~m} \\
0 \mathrm{~m}\end{array}$ & $\begin{array}{l}102 \mathrm{~m}^{3} / \mathrm{s} \\
102 \mathrm{~m}^{3} / \mathrm{s}\end{array}$ \\
\hline & 3. Fixed & $0 \mathrm{~m}$ & 0.2 & 1 & $3 \mathrm{~m}$ & $0 \mathrm{~m}$ & $200 \mathrm{~m}^{3} / \mathrm{s}$ \\
\hline & 4. Fixed & $0 \mathrm{~m}$ & 0.2 & 1 & $3 \mathrm{~m}$ & $0 \mathrm{~m}$ & $200 \mathrm{~m}^{3} / \mathrm{s}$ \\
\hline
\end{tabular}

The relevant portion of the w2_selective.npt file is as follows:

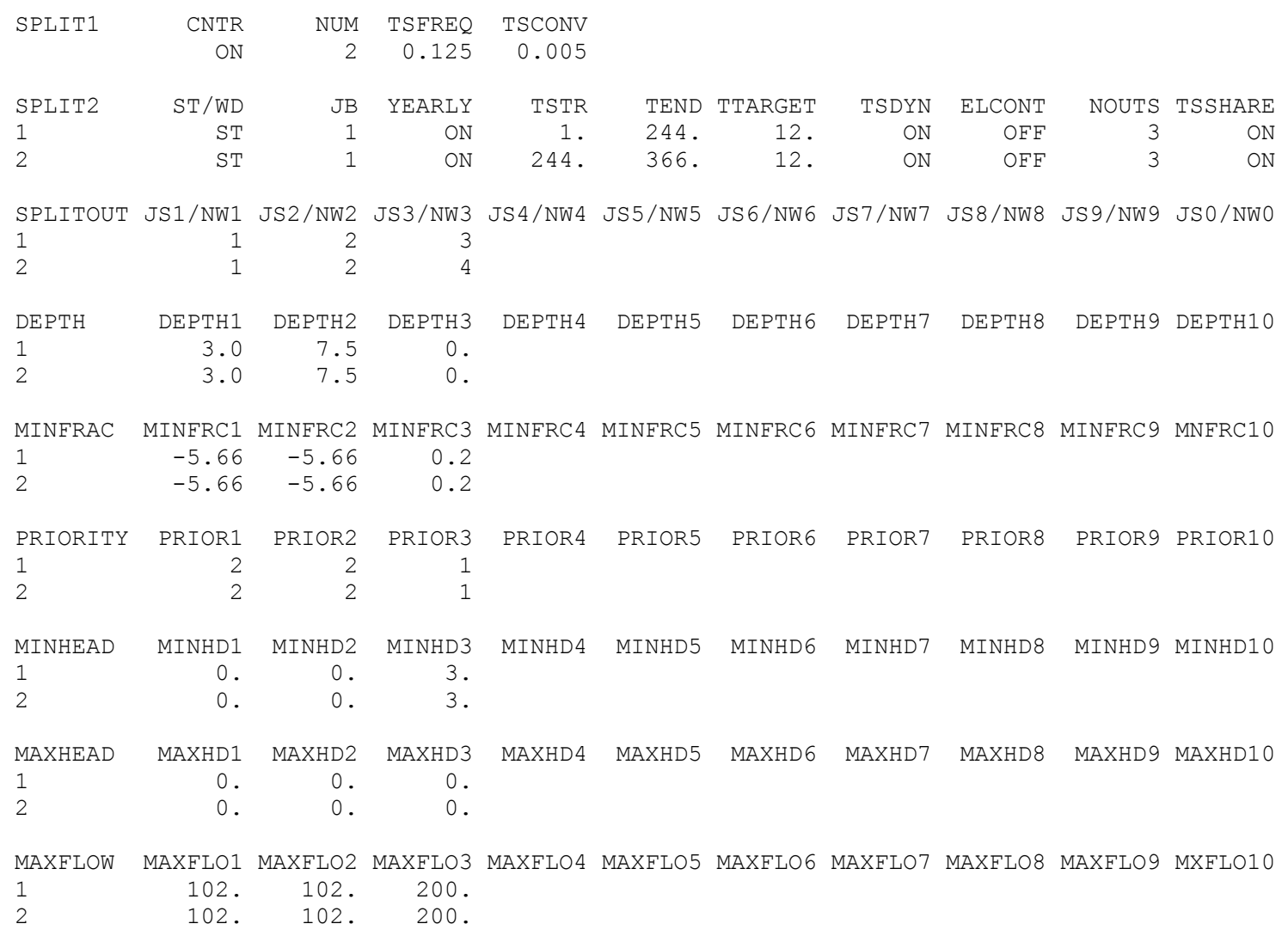

Figure 8. Example 5 uses two floating outlets that share the flow for the lower priority (set B) outlets because TSSHARE is set to ON. For January through August, flows through the floating outlets are blended with the highest-elevation fixed outlet. For the remainder of the year, the lowest-elevation fixed outlet is blended with the floating outlets. All outlets have some minimum and maximum flow constraints. 


\section{Comparison Test of New Algorithms}

The modified model algorithms were tested with models of Detroit Lake in northwestern Oregon. Detroit Dam was constructed in 1953 by USACE on the North Santiam River and resulted in the formation of Detroit Lake (fig. 9). The North Santiam River is one of several major tributaries to the Willamette River, and Detroit Dam is the tallest dam (141 m [463 ft]) in the Willamette River Basin. The lake captures several rivers that drain an area on the western slopes of Mt. Jefferson in the Cascade Range, and impounds $5.61 \times 10^{8} \mathrm{~m}^{3}(455,100$ acre-ft) of water at full pool, making it one of the largest reservoirs in the Willamette River Basin.

A set of model scenarios from a previously calibrated version 3.1.2 CE-QUAL-W2 model of Detroit Lake (Sullivan and others, 2007; Buccola and others, 2012) was used as a comparison test against the new version 3.7 modified blending algorithms. The results previously documented by Buccola and others (2012) were from a version 3.1.2 model that had a similar, but not exactly the same, implementation of most of the blending algorithm documented here for version 3.7. The USGS Detroit Lake model originally was calibrated to conditions that occurred during calendar years 2002 and 2003, and was tested for high-flow conditions during selected months of the winter of 2005-06. The model scenarios, however, were run using three sets of environmental conditions lasting one year each and representing cool/wet, normal, and hot/dry conditions drawn from the historical record.

In this test comparison, a structural model scenario was applied in which a hypothetical floating outlet was used in conjunction with a lower fixed-elevation outlet to try to meet a user-specified timeseries of target release temperatures under the cool/wet, normal, and hot/dry environmental conditions. The fixed-elevation outlet was given a centerline elevation of $408.4 \mathrm{~m}(1,340 \mathrm{ft})$. The floating outlet was given a depth (DEPTH) of $2 \mathrm{~m}(6.56 \mathrm{ft})$ and a minimum flow of $11.327 \mathrm{~m}^{3} / \mathrm{s}\left(400 \mathrm{ft}^{3} / \mathrm{s}\right.$; MINFRAC $=-11.327$ ). This is the "uro-float_400fmin" scenario (runs c14, n14, and h14) as documented by Buccola and others (2012). The outlets and blending inputs are illustrated in figure 10. 


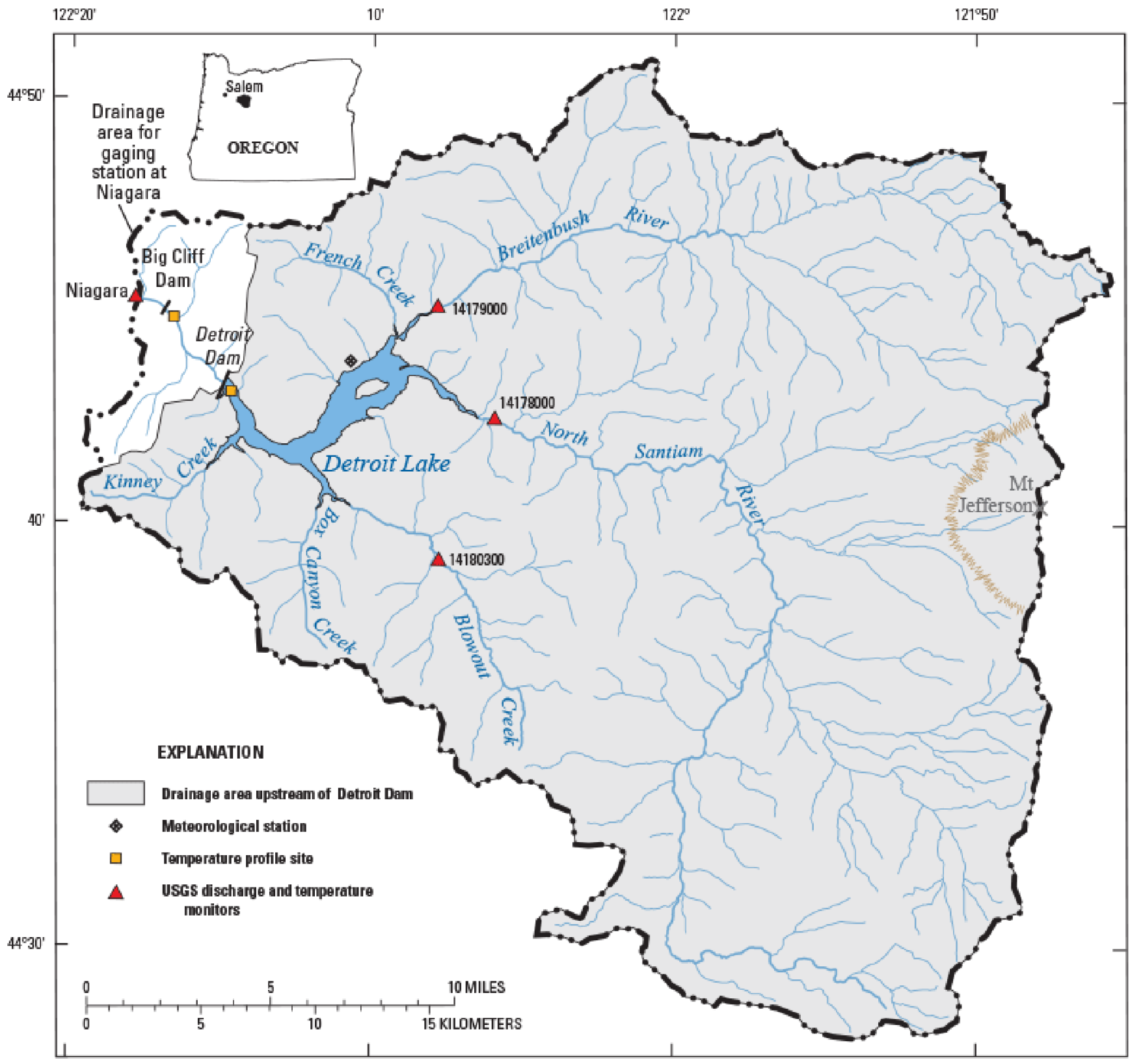

Base map modified from U.S. Geological Surwey digital data (1:24,000). Projection: UTM, Zone 10, North American Datum of 1927.

Figure 9. Map showing location of Detroit Lake and Detroit Dam in the North Santiam River Basin, northwestern Oregon. (Map from Buccola and others, 2012.) 


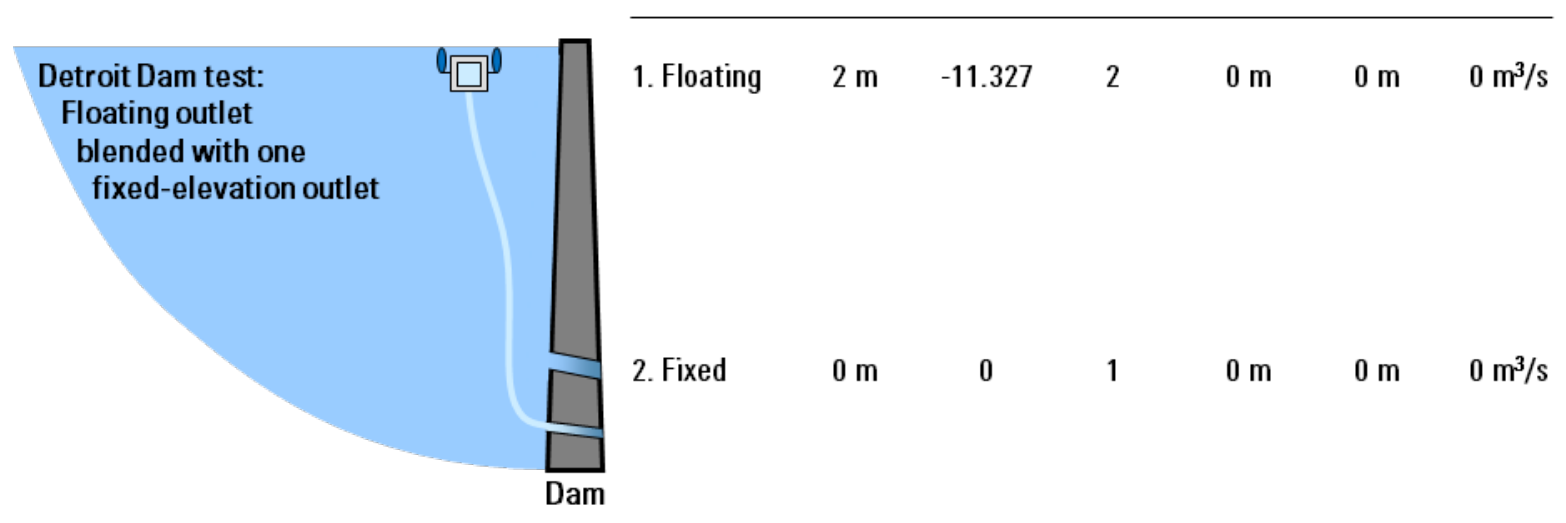

Figure 10. Outlets and user specifications for the Detroit Lake comparison test.

Running these scenarios with both the version 3.1.2 and 3.7 modified models produced quite similar results (figs. 11 and 12). Slightly less day-to-day variability and better adherence to the temperature target was apparent in the version 3.7 results as compared to those from version 3.1.2. The decrease in variability and better adherence to the targets is likely due to several factors:

1. more frequent recalculation of the blending flow fractions in version 3.7,

2. a more stringent convergence criterion in version 3.7 , and

3. better handling of blending during power-peaking conditions.

The version 3.1.2 algorithms were set up to minimize dam-operator labor by allowing the user to limit the number of times per day that gate positions are changed; as a result, the blending flow fractions were recalculated only once per day at 5:00 a.m. in that model run. In contrast, the blending flow fractions were recalculated in the version 3.7 model run every 3 hours, as specified by the TSFREQ input variable ( 0.125 days). The version 3.7 code is not yet set up to take into account the actual time of day that dam operators might have to make a change in releases. 

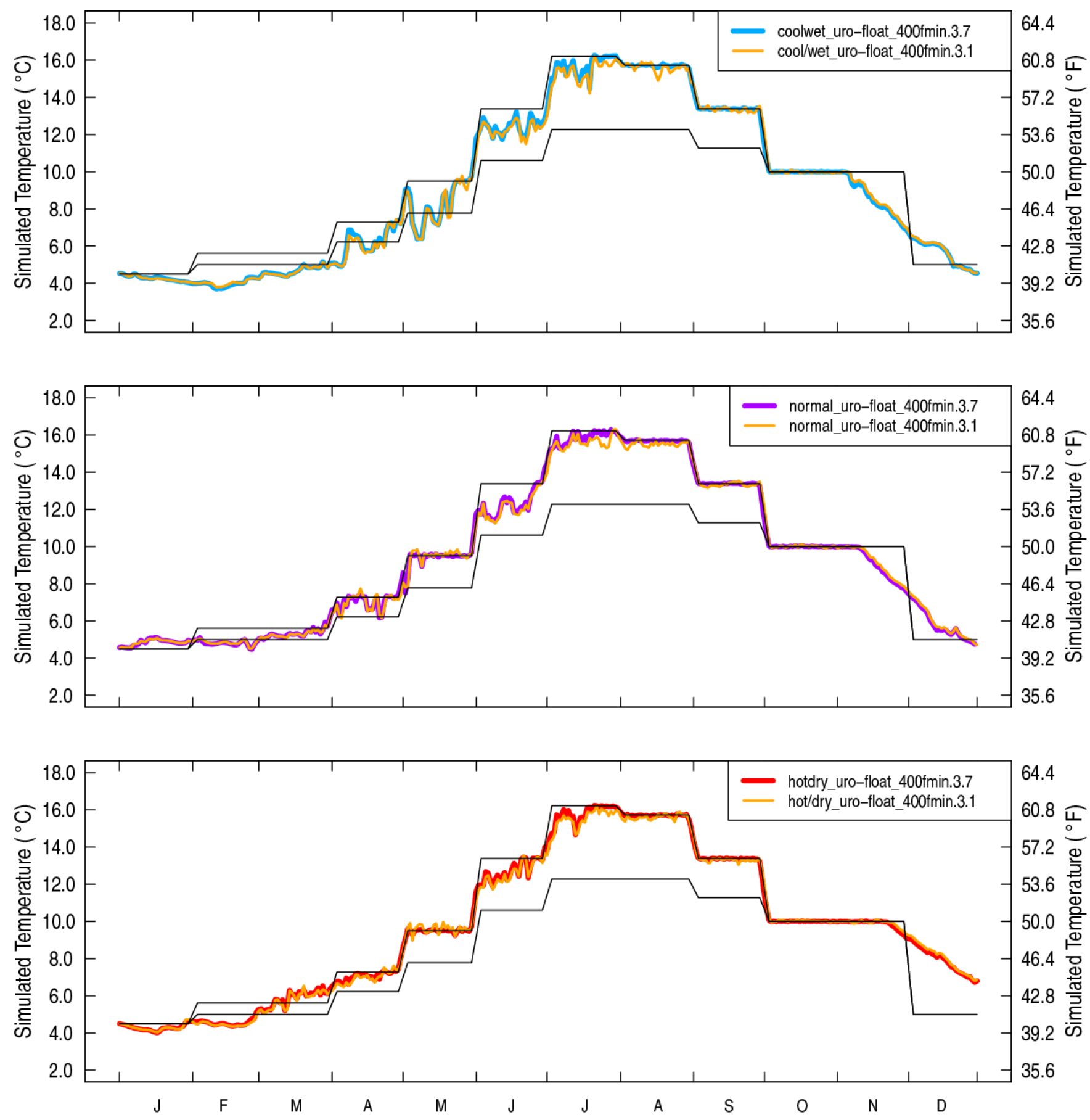

Figure 11. Comparison of daily mean release temperatures resulting from the use of blending algorithms in CE-QUAL-W2 version 3.1.2 (v3.1) and version 3.7 (v3.7) and applied to Detroit Lake, northwestern Oregon, for three environmental conditions: (A) cool/wet, (B) normal, and (C) hot/dry. The black lines indicate the minimum and maximum monthly temperature targets; only the maximum target was used in the model runs. 


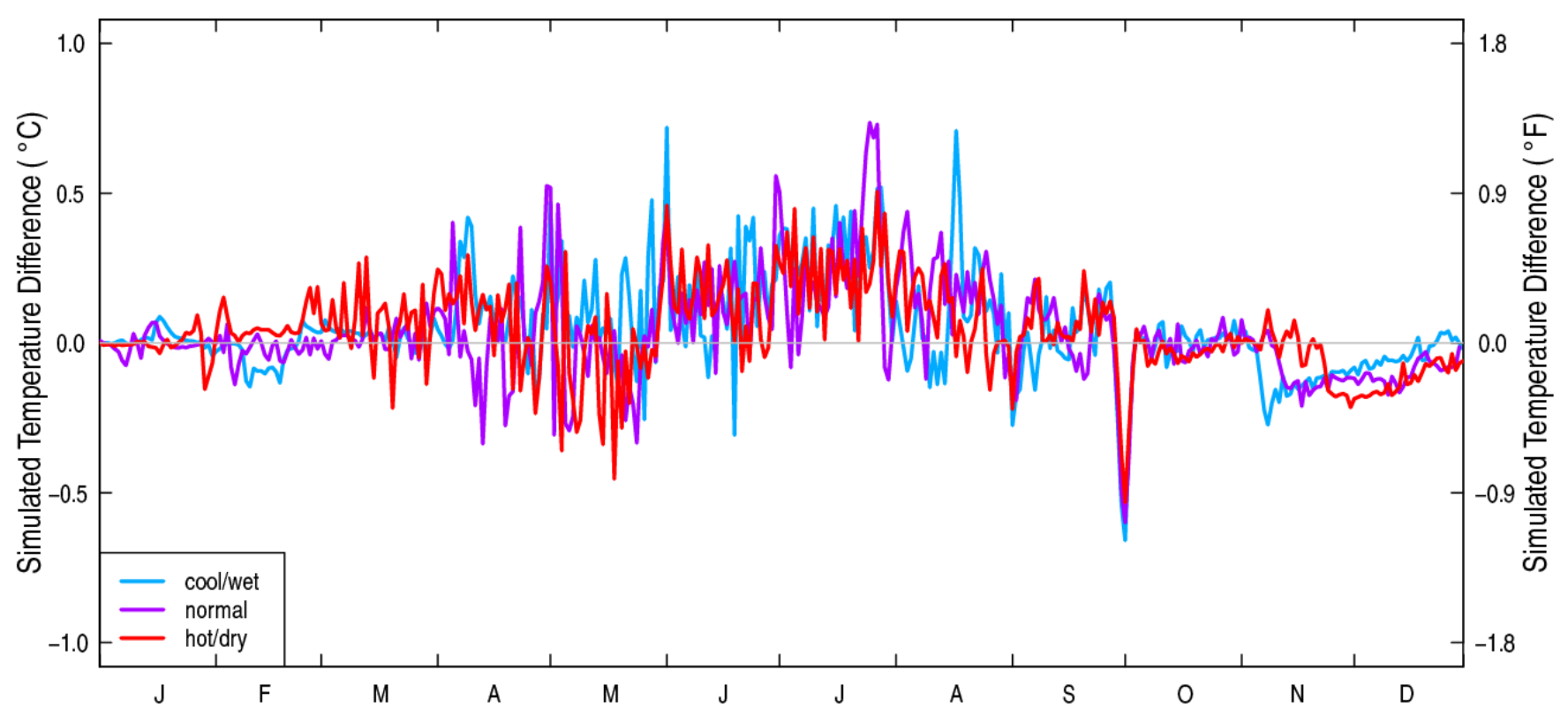

Figure 12. Difference in the daily mean release temperatures (version 3.7 results minus version 3.1 .2 results) from the "uro-float_400fmin" scenario as applied to Detroit Lake, northwestern Oregon, for three sets of environmental conditions (cool/wet, normal, and hot/dry).

Most of the simulated daily mean temperature differences between versions 3.7 and 3.1 .2 in these scenarios were less than $0.5^{\circ} \mathrm{C}$ (about $0.9^{\circ} \mathrm{F}$, fig. 12). Some larger differences occurred during mid-summer for short periods (not exceeding 3 days in length), but did not persist at any substantial level later in autumn. Minor differences (less than $0.3^{\circ} \mathrm{C}$, or about $0.5^{\circ} \mathrm{F}$ ) between the predictions of the two model versions also were apparent in autumn (see cool/wet scenario during November [fig. 12]), but the seasonal patterns were still captured well by both versions.

Other hypothetical tests were performed separately with the new code to ensure that all new capabilities worked as intended, including the priority designations and the criteria for minimum and maximum head and minimum and maximum flows. The tests all showed that the new model code performed as expected. Additional examples of how the new model features can be implemented in a variety of blending scenarios for Detroit Lake are documented by Buccola and others (2015). 


\section{Summary and Conclusions}

The algorithm in version 3.7 of the CE-QUAL-W2 model for blending releases from multiple dam outlets to meet a target release temperature was modified to add new options and increased functionality. The modified algorithm allows releases from up to 10 outlets (rather than the original 2) to be blended, and an external time-series of user-specified temperatures can be specified as the target release temperature. Fixed-elevation outlets can be changed into floating outlets by specifying a nonzero depth relative to the water surface. Minimum and maximum head constraints can be set for each blended outlet such that the outlet will not be used if its centerline elevation is shallower than the minimum head criterion or deeper than the maximum head criterion. Minimum and maximum flow criteria also can be set for each of the blended outlets. Priority designations can be set for each blended outlet to help in choosing which outlets to use and in determining which outlets receive a greater proportion of the flow in certain situations. Lastly, an iterative solution technique was implemented to increase the accuracy of the blending calculations each time the subroutine is called. Through the use of these new options, USGS staff have found that a wide range of hypothetical structures and complicated operational release strategies at dams can be implemented somewhat automatically by the model, thus decreasing the number of model runs required to obtain a specific result, and decreasing the amount of preprocessing of inputs required to properly constrain the conditions for testing a hypothetical operational or structural scenario.

The modified version 3.7 model code was tested with a variety of example configurations and also was compared against a previously calibrated version 3.1.2 CE-QUAL-W2 model of Detroit Lake in northwestern Oregon. Results from the comparison showed that the predictions were largely the same, but with more stable results from version 3.7 that might have been due to more frequent blending calculations each day as well as some refinements in the iterative solution technique.

\section{Acknowledgments}

This work was done in collaboration with the U.S. Army Corps of Engineers (USACE), Portland District. Kathryn Tackley and Dan Turner of USACE provided data, helpful discussions, and insights with respect to the types of capabilities to build into the improved model algorithms. Discussions with Scott Wells and Chris Berger at Portland State University resulted in code improvements and additional features. Thanks also to Annett Sullivan and Adam Stonewall of USGS for assistance in testing the new algorithms.

\section{Supplementary Material}

The modified version 3.7 model source code, compiler options, and compiled binaries (generic or with the Intel Visual Fortran (IVF) user interface) used in this study are available for download from the website of this report (http://pubs.usgs.gov/of/2015/1027/).

\section{References Cited}

Buccola, N.L., and Rounds, S.A., 2011, Simulating potential structural and operational changes for Detroit Dam on the North Santiam River, Oregon-Interim Results: U.S. Geological Survey Open-File Report 2011-1268, 32 p. [Also available at http://pubs.usgs.gov/of/2011/1268/.] 
Buccola, N.L, Rounds, S.A., Sullivan, A.B., and Risley, J.C., 2012, Simulating potential structural and operational changes for Detroit Dam on the North Santiam River, Oregon, for downstream temperature management: U.S. Geological Survey Scientific Investigations Report 2012-5231, 68 p. [Also available at http://pubs.usgs.gov/sir/2012/5231/.]

Buccola, N.L., Stonewall, A.J., and Rounds, S.A., 2015, Simulations of a hypothetical temperature control structure at Detroit Dam on the North Santiam River, northwestern Oregon: U.S. Geological Survey Open-File Report 2015-1012, 30 p. [Also available at http://pubs.usgs.gov/of/2015/1012.]

Caissie, D., 2006, The thermal regime of rivers-A review: Freshwater Biology, v. 51, p. 1389-1406.

Cole, T.M., and Wells, S.A., 2002, CE-QUAL-W2-A two-dimensional, laterally averaged, hydrodynamic and water-quality model, version 3.1: U.S. Army Corps of Engineers, Instruction Report EL-02-1 [variously paged].

Cole, T.M., and Wells, S.A., 2011, CE-QUAL-W2-A two-dimensional, laterally averaged, hydrodynamic and water-quality model, version 3.7: U.S. Army Corps of Engineers, Instruction Report EL-11-1 [variously paged].

Collier, Michael, Webb, R.H., and Schmidt, J.C., 1996, Dams and rivers-Primer on the downstream effects of dams: U.S. Geological Survey Circular 1126, 94 p. [Also available at

http://pubs.er.usgs.gov/usgspubs/cir/cir1126.]

Hanna, R.B., Saito, L., Bartholow, J.M., and Sandelin, J., 1999, Results of simulated temperature control device operations on in-reservoir and discharge water temperatures using CE-QUAL-W2: Journal of Lake and Reservoir Management, v. 15, no. 2, p. 87-102.

National Marine Fisheries Service, 2008, Willamette Basin Biological Opinion-Endangered Species Act, Section 7(a)(2), Consultation: National Oceanic and Atmospheric Administration Fisheries Log Number F/NWR/2000/02117 [variously paged], accessed June 3, 2014, at https://pcts.nmfs.noaa.gov/pctsweb/dispatcher/trackable/NWR-2000-2117.

Portland State University Water Quality Research Group, 2012, CE-QUAL-W2 model description: Portland State University Water Quality Research Group, accessed April 26, 2012, at $h t t p: / / w w w . c e e . p d x . e d u / w 2 /$.

Risley, J.C., Constantz, J.A., Essaid, H.I., and Rounds, S.A., 2010, Effects of upstream dams versus groundwater pumping on stream temperature under varying climate conditions: Water Resources Research, v. 46, no. 6, W06517, doi: 10.1029/2009WR008587. [Also available at $h t t p: / / d x . d o i . o r g / 10.1029 / 2009$ WR008587.]

Rounds, S.A., 2010, Thermal effects of dams in the Willamette River basin, Oregon: U.S. Geological Survey Scientific Investigations Report 2010-5153, 64 p. [Also available at $h t t p: / / p u b s . u s g s . g o v / s i r / 2010 / 5153 /$.

Rounds, S.A., and Sullivan, A.B., 2006, Development and use of new routines in CE-QUAL-W2 to blend water from multiple reservoir outlets to meet downstream temperature targets, in Proceedings of the Third Federal Interagency Hydrologic Modeling Conference, April 2-6, 2006, Reno, NV: Subcommittee on Hydrology of the Interagency Advisory Committee on Water Information, ISBN 0-9779007-0-3. [Also available at http://or.water.usgs.gov/tualatin/fihmc3_w2_modifications.pdf.]

Rounds, S.A., and Wood, T.M., 2001, Modeling water quality in the Tualatin River, Oregon, 1991-1997: U.S. Geological Survey Water-Resources Investigations Report 01-4041, 53 p. [Also available at http://or.water.usgs.gov/pubs_dir/Online/Pdf/01-4041.pdf.]

Sullivan, A.B., and Rounds, S.A., 2006, Modeling water-quality effects of structural and operational changes to Scoggins Dam and Henry Hagg Lake, Oregon: U.S. Geological Survey Scientific Investigations Report 20065060, 36 p. [Also available at http://pubs.usgs.gov/sir/2006/5060/.]

Sullivan, A.B., Rounds, S.A., Asbill-Case, J.R., and Deas, M.L., 2013, Macrophyte and pH buffering updates to the Klamath River water-quality model upstream of Keno Dam, Oregon: U.S. Geological Survey Scientific Investigations Report 2013-5016, 52 p. [Also available at http://pubs.usgs.gov/sir/2013/5016/.]

Sullivan, A.B., Rounds, S.A., Sobieszczyk, S., and Bragg, H.M., 2007, Modeling hydrodynamics, water temperature, and suspended sediment in Detroit Lake, Oregon: U.S. Geological Survey Scientific Investigations Report 2007-5008, 40 p. [Also available at http://pubs.usgs.gov/sir/2007/5008/.] 


\section{Appendix 1. Example w2_selective.npt Files}

The w2_selective.npt input file contains all user-input variables for the blending of outflows to meet a downstream temperature target. The six examples in this appendix reflect each of the examples used in this report to demonstrate certain user inputs and model capabilities. See the examples and the comparison test in the body of the report for more information.

\section{Example 1: w2_selective.npt file}

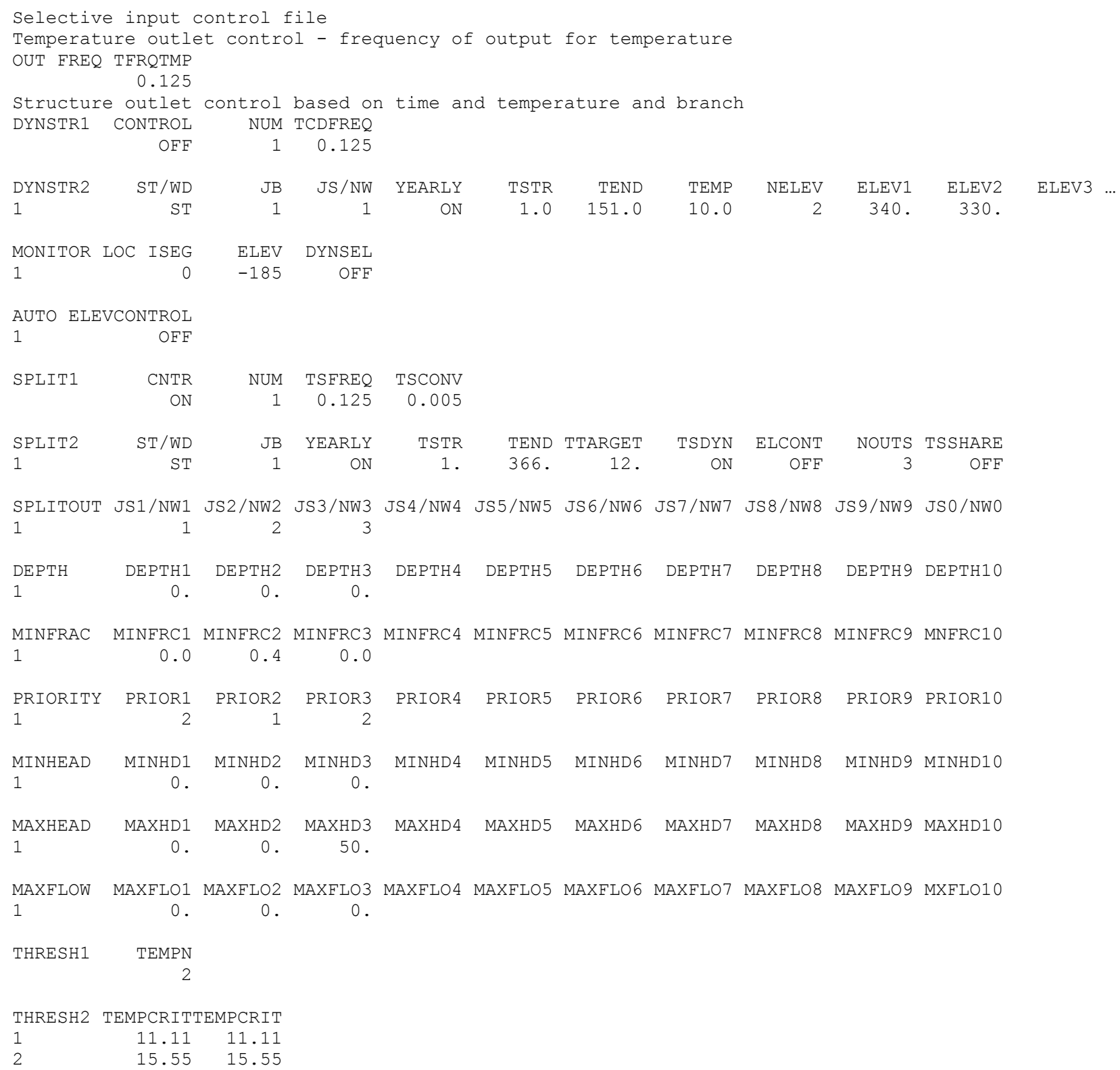




\section{Example 2: w2_selective.npt file}

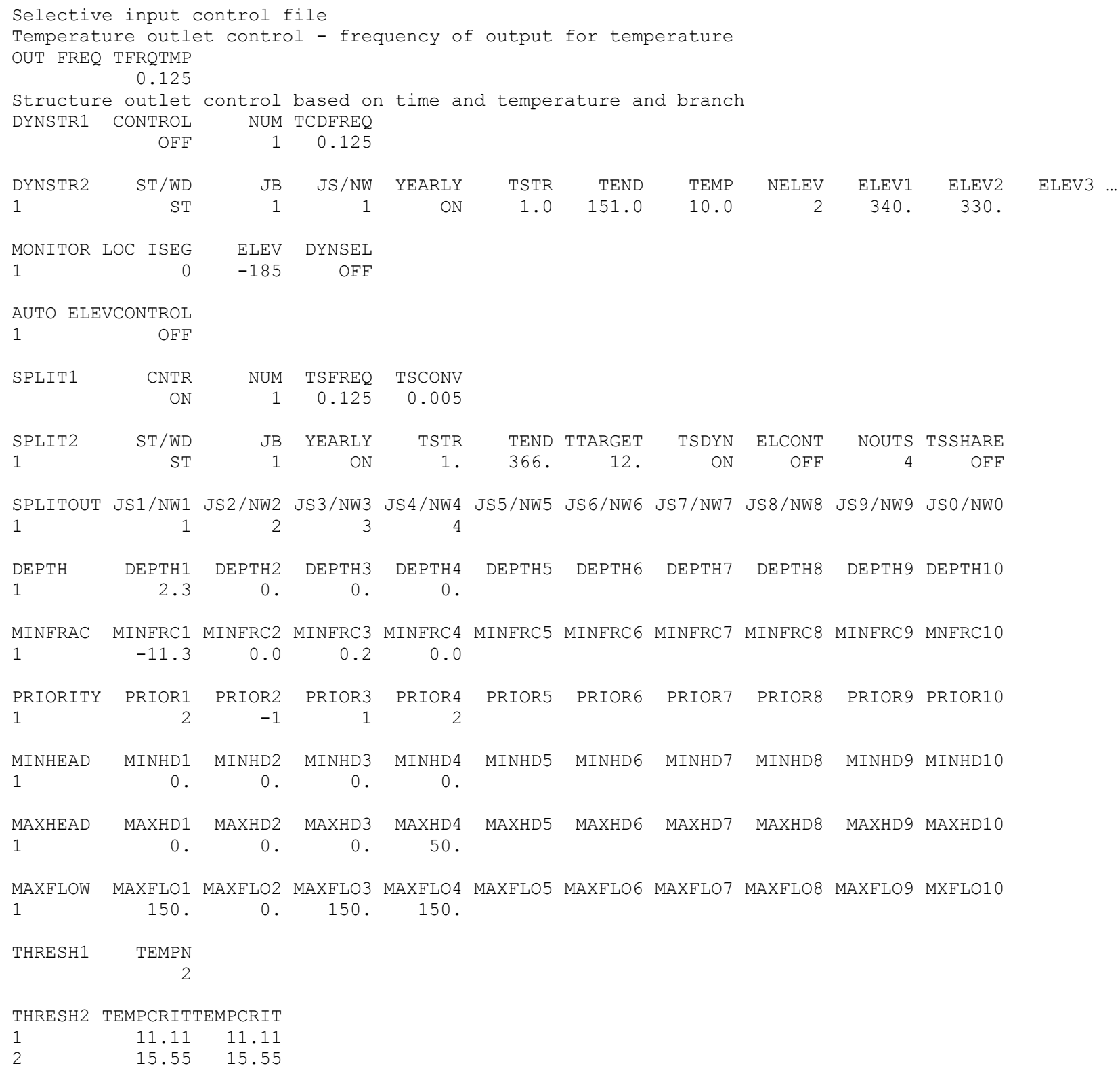




\section{Example 3: w2_selective.npt file}

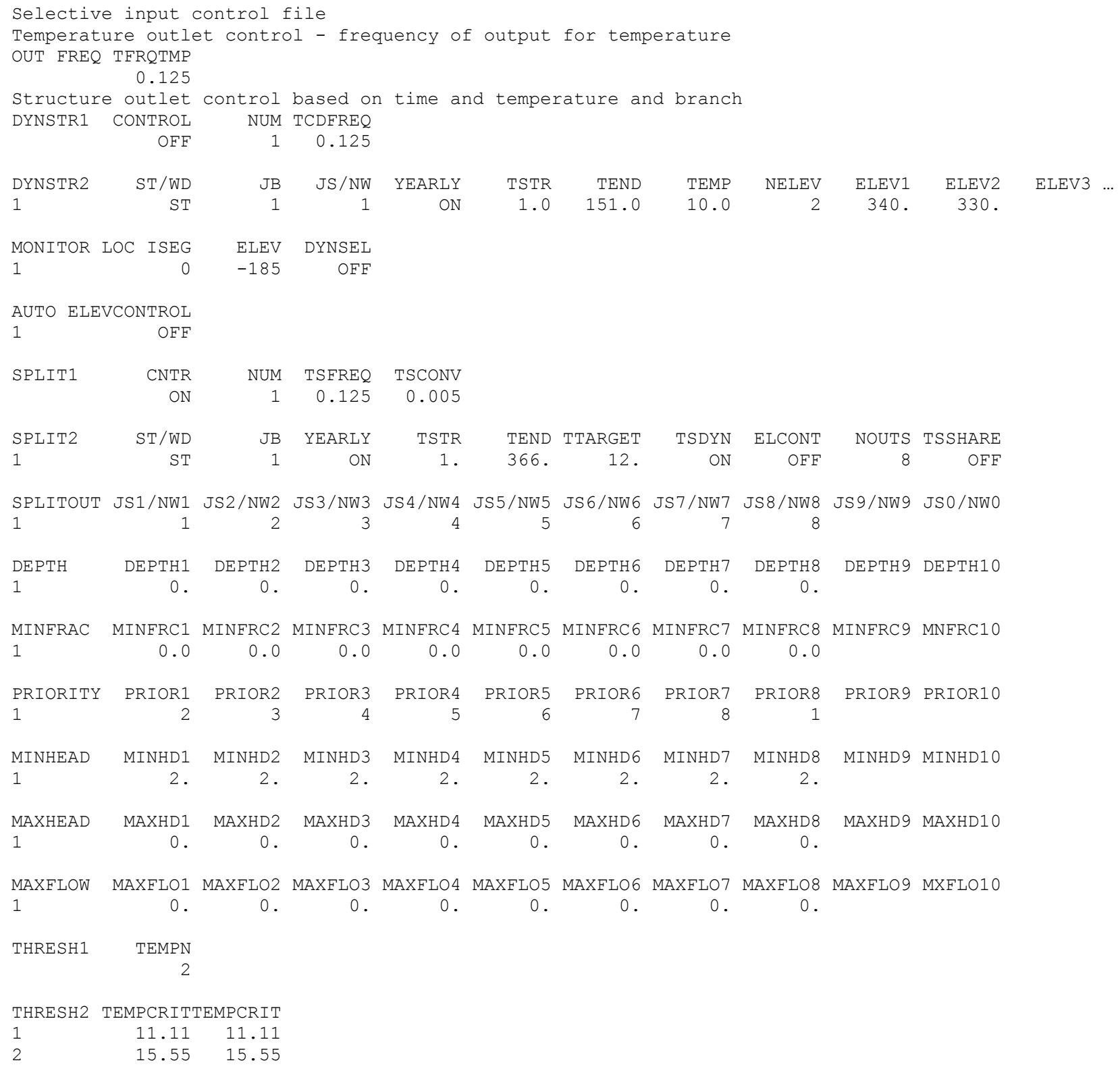




\section{Example 4: w2_selective.npt file}

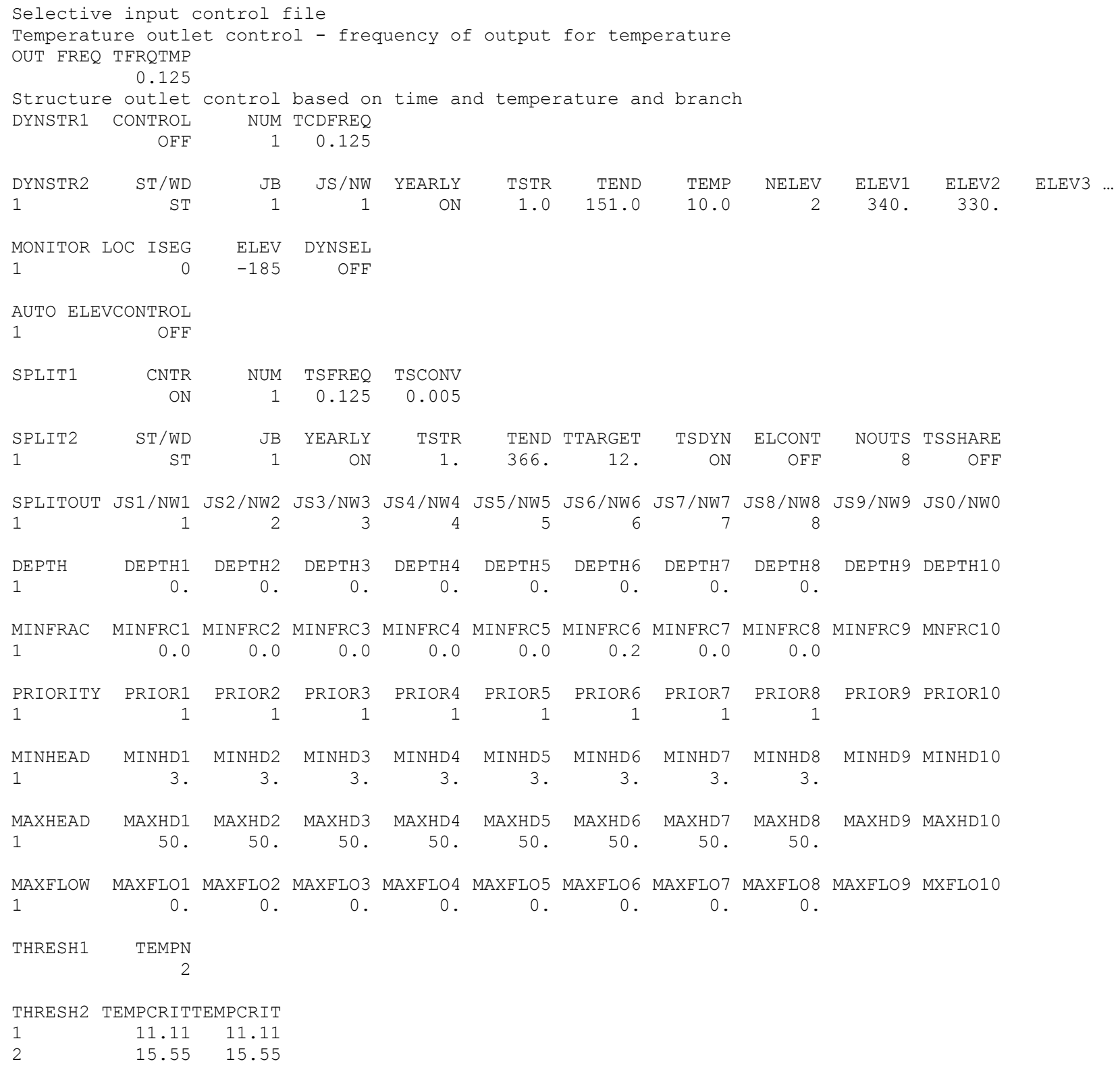




\section{Example 5: w2_selective.npt file}

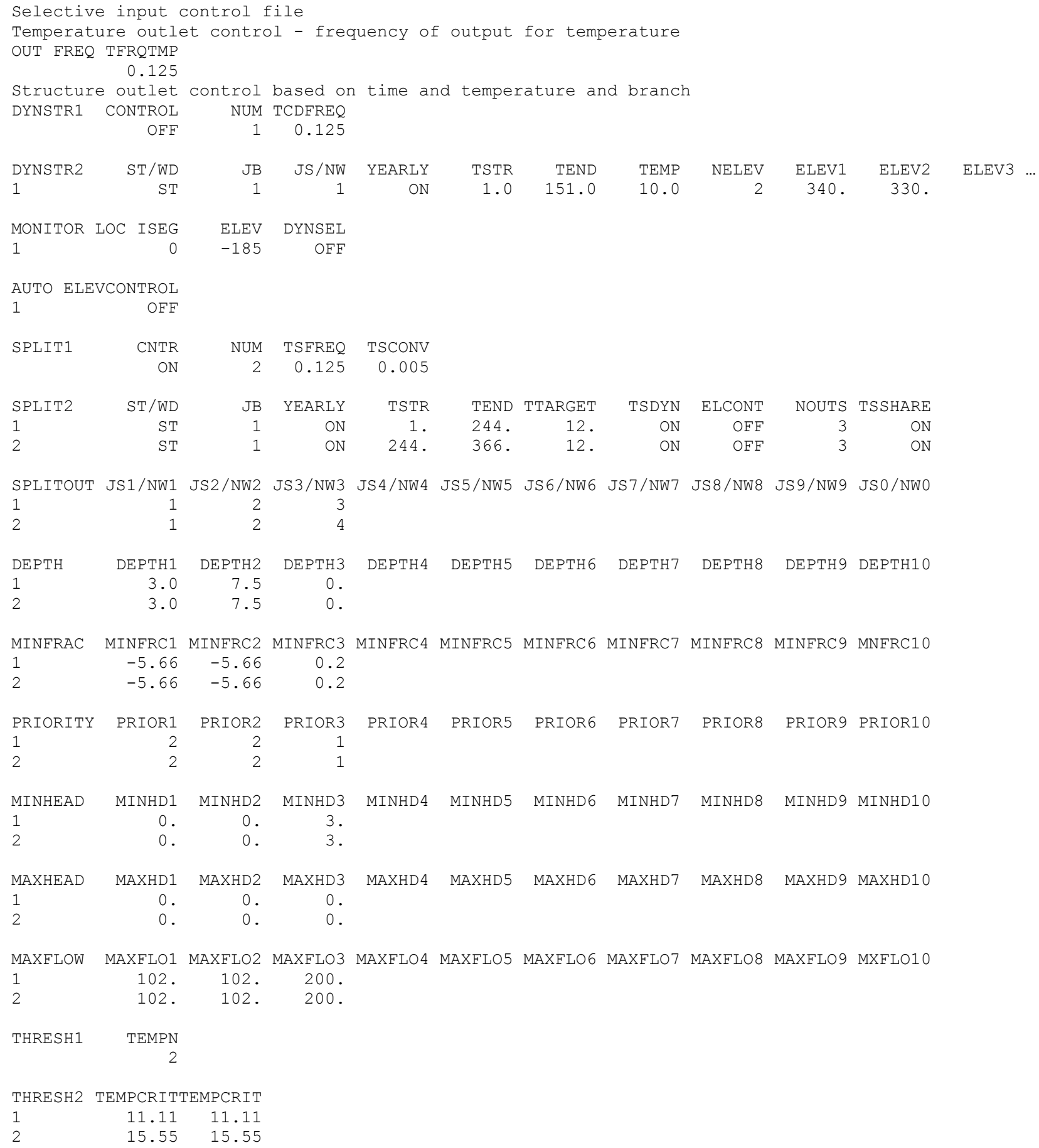




\section{Comparison Test: w2_selective.npt file}

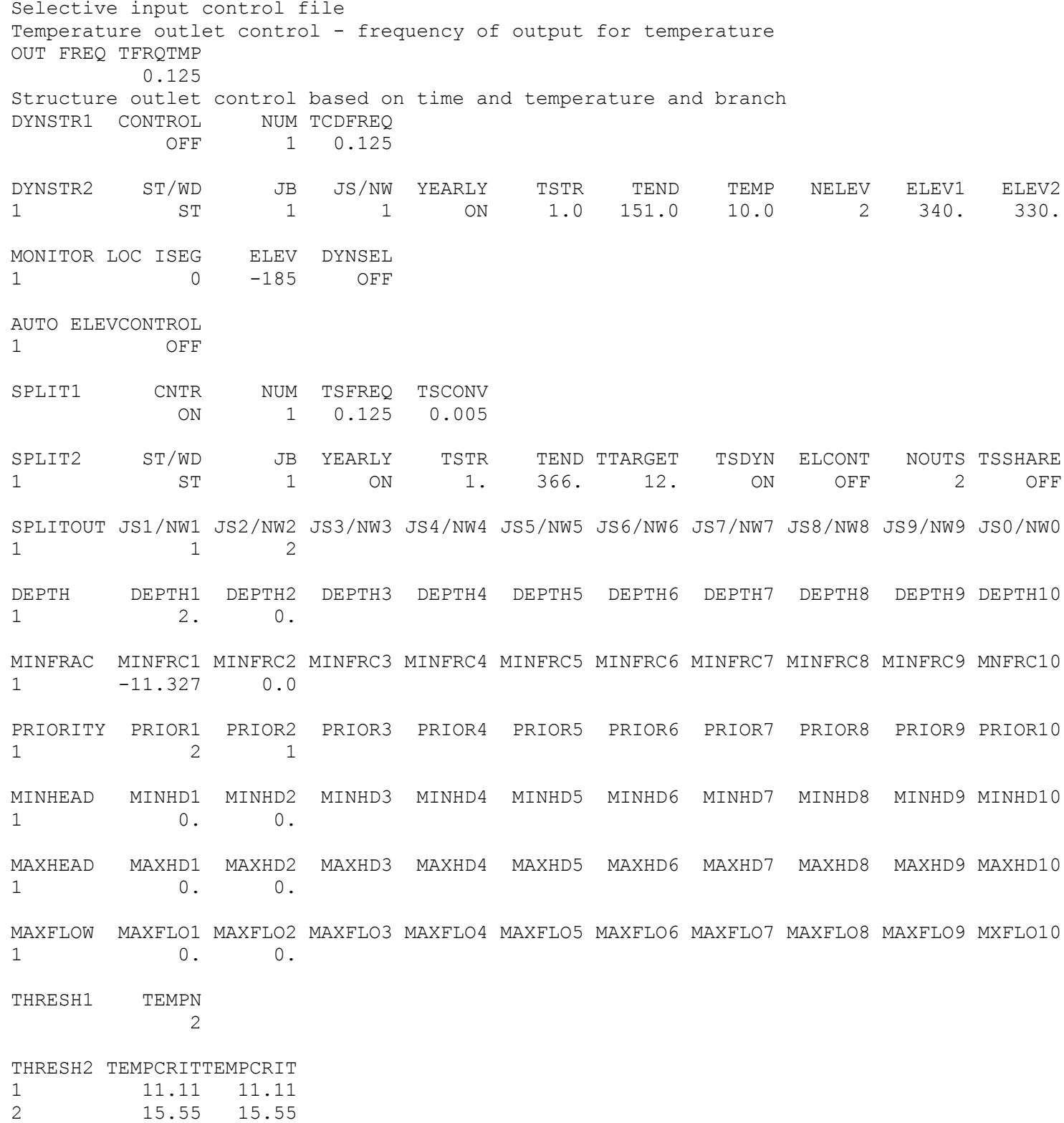


Publishing support provided by the U.S. Geological Survey Science Publishing Network, Tacoma Publishing Service Center

For more information concerning the research in this report, contact the Director, Oregon Water Science Center

U.S. Geological Survey

2130 SW 5th Avenue

Portland, Oregon 97201

http://or.water.usgs.gov 
